\title{
Hospital Epidemiology and Infection Control in the Transplant Center
}

\author{
Gopi Patel and Sarah Hochman
}

\section{Contents}

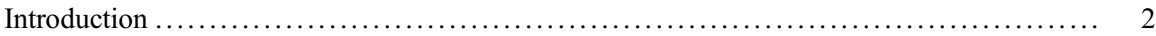

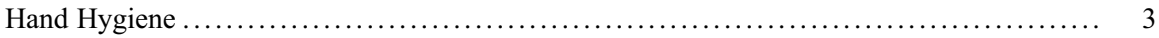

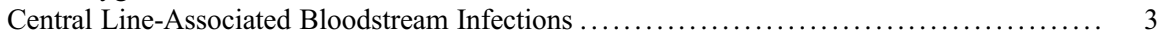

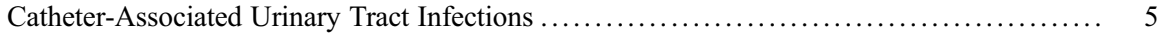

Clostridioides difficile ....................................................... 6

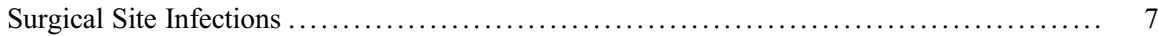

Preventing Infections Associated with the Healthcare Environment $\ldots \ldots \ldots \ldots \ldots \ldots \ldots \ldots, \quad 8$

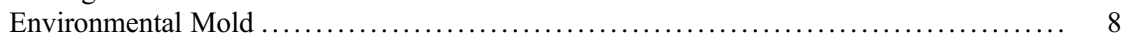

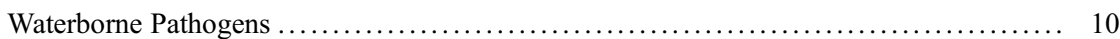

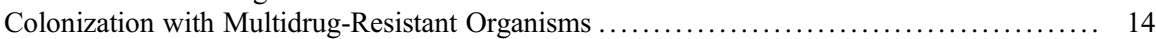

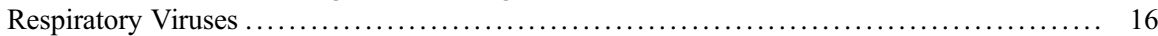

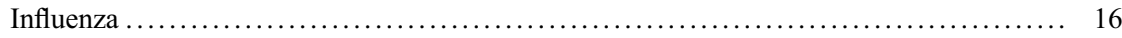

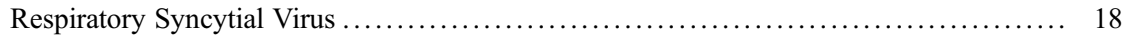

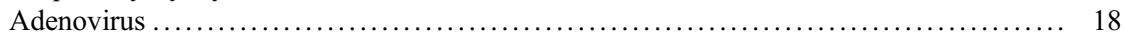

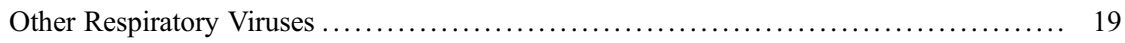

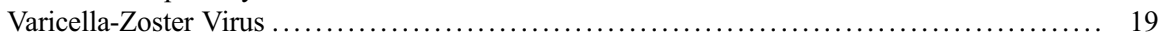

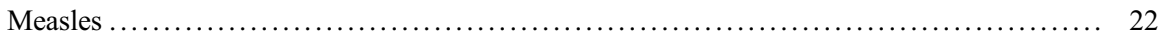

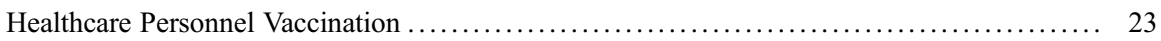

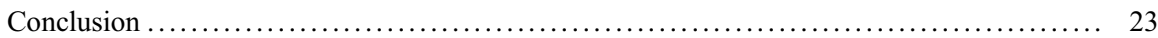

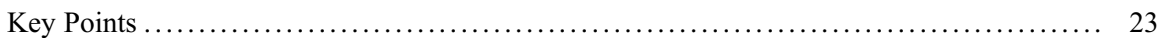

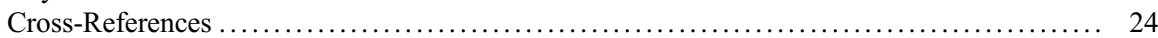

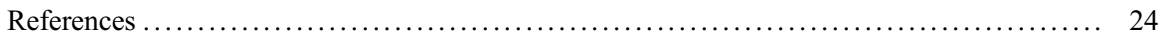

G. Patel (两)

Department of Medicine, Division of Infectious Diseases, Icahn School of Medicine at Mount Sinai, New York, NY, USA

e-mail: gopi.patel@mountsinai.org

\section{S. Hochman}

Department of Medicine, Division of Infectious Disease and Immunology, New York University School of Medicine, New York, NY, USA

e-mail: sarah.hochman@nyulangone.org 


\section{Abstract \\ Both solid organ and hematopoietic stem cell transplant candidates and recipients are at high risk for healthcare-associated infections due to their underlying diseases, comorbid conditions, as well as the receipt of augmented immunosup- pression to prevent rejection. Partnership between transplant physicians, institu- tional leaders, and infection preventionists allows for the accommodation of this growing vulnerable patient population into institutional risk assessments and hazard analyses. In addition, advancements in diagnostics and molecular typing have provided important information regarding sources of transmission of multi- drug-resistant or opportunistic pathogens, thus informing strategies for mitigating risk and controlling outbreaks. Here we review common healthcare-associated infections and strategies for source control, prevention, and curbing outbreaks when detected.}

\section{Keywords}

Infection control $\cdot$ Surgical site infections (SSIs) $\cdot$ Clostridioides difficile multidrug-resistant organism $\cdot$ Influenza $\cdot$ Respiratory syncytial virus $\cdot$ Hand hygiene $\cdot$ Legionella $\cdot$ Nontuberculous mycobacteria (NTM) $\cdot$ Central lineassociated bloodstream infection (CLABSI) - Catheter-associated urinary tract infection $(\mathrm{CAUTI}) \cdot$ Opportunistic premise plumbing pathogens (OPPP)

\section{Introduction}

Despite significant advancements in immunosuppression, prophylactic strategies, and pre- and posttransplant management, candidates and recipients of both solid organ and hematopoietic stem cell transplants continue to be at higher risk for healthcare-associated infections when compared to other patients. Prolonged wait times and new allocation systems leave some patients reliant on indwelling devices like central venous catheters, ventilators, and urinary catheters both before and after transplantation, and the hospital environment itself serves as a potential source for infections with opportunistic pathogens. Improved access to molecular diagnostics and molecular typing has improved the ability to identify outbreaks and address source control. In addition, application of process improvement techniques and partnering between institutional and transplant leadership and infection prevention and control have led to a remarkable improvement in outcomes that were once considered inherent to transplant including healthcare-associated infections.

Here we review select infection prevention strategies that are applicable to transplant patients and review specific pathogens that pose risk to both candidates and recipients. General infection prevention practices are applicable to these vulnerable patient populations and include hand hygiene, respiratory hygiene, vaccination promotion, adherence to care bundles, and antimicrobial stewardship. In addition, patient placement and targeted surveillance for specific pathogens and syndromes may have a pivotal role in the prevention of infection with certain infections. 


\section{Hand Hygiene}

Hand hygiene is one of the most basic yet important aspects of infection prevention and control. Viruses, bacteria, and fungi can all be spread to and from the environment, staff, and patients via the hands of healthcare personnel (HCP). Hand hygiene prevents horizontal transmission of multidrug-resistant organisms (MDROs), including Clostridioides difficile, and reduces the risk of healthcare-associated infections (HAI). Despite this knowledge, HCP hand hygiene is poor even when working with vulnerable transplant recipients [1], highlighting the need for targeted interventions. Clinical staff and patients should have easy access to sinks and alcohol-based hand rub (ABHR) as part of a comprehensive strategy to improve compliance [2]. Prospective monitoring through direct observation or electronically assisted monitoring with real-time feedback can increase hand hygiene compliance $[3,4]$.

Patient hand hygiene is also important for infection prevention. Patient hand contamination with MDROs is common, and this can be transmitted to and from their environment [5]. An observational study of transplant recipients confirmed that hand hygiene compliance among patients is low, possibly contributing to pathogen transmission [6]. Visitor hand hygiene is important because visitors frequently touch surfaces in the healthcare environment that are also touched by both patients and HCP, thereby increasing the risk of transmission of nosocomial pathogens [7]. Thus, patient and visitor education encouraging hand hygiene and instructing the proper way to perform hand hygiene should be incorporated into a multimodal program addressing infection prevention.

\section{Central Line-Associated Bloodstream Infections}

Central venous catheters (CVCs) are used frequently in the pre- and posttransplant period for hemodynamic monitoring, blood sampling, and administration of medications and blood products. In addition to the convenience of direct venous access, they confer a risk of infection due to bypassing of the protective barrier of the skin. Central line-associated bloodstream infections (CLABSI) are a dangerous complication of CVCs, conferring increased length of stay, increased healthcare costs, and increased mortality risk $[8,9]$.

Transplant recipients and those awaiting transplant are at high risk for CLABSI, due to high prevalence of CVCs, prolonged hospital lengths of stay, prolonged duration of CVCs, and compromised immunity. Patients awaiting heart transplant frequently have pulmonary artery catheters, which allow for continuous monitoring of left ventricular filling pressures and confer a high urgency status for transplantation. At one institution, the CLABSI rate for patients with pulmonary artery catheters was five times higher than the CLABSI rate for intensive care unit (ICU) patients [10].

Patients who are pre- or immediately post-hematopoietic stem cell transplantation (HSCT) are at additional risk for bloodstream infections secondary to mucosal 
barrier injuries due to prolonged neutropenia. Single-center studies focusing on HSCT patients report a $20-60 \%$ incidence of bloodstream infections in the immediate posttransplant period and higher incidence in patients with acute graftversus-host disease (GVHD) compared with rates prior to development of GVHD $[11,12]$. HSCT candidates undergoing conditioning and HSCT recipients should perform oral hygiene throughout the day to reduce the risk of oral mucositis and secondary bacteremia [13].

A care bundle is a group of evidence-based practices which when performed together are associated with improved outcomes. Each included intervention is considered good practice. Compliance with care bundles should be audited, and feedback should be given to improve compliance and address barriers to compliance. Bundled interventions have proved to decrease CLABSI in ICUs and prompted a paradigm shift. CLABSI now were considered avoidable, and in many centers transplant populations are highlighted for increased incidence of CLABSI [14].

Indeed the majority of CLABSI are likely preventable. In a pivotal statewide trial, the implementation of a CVC insertion bundle including hand hygiene, full barrier precautions, cleaning the insertion site with chlorhexidine gluconate $(\mathrm{CHG})$, avoiding the femoral site, and removing unnecessary CVCs resulted in a 66\% sustained decrease in CLABSI in the ICU setting [15]. Additional strategies to prevent CLABSI focus on maintenance of the necessary CVC. These include daily CHG bathing to reduce the bacterial load on the skin and daily patient hygiene $[12,16]$; disinfection of catheter hubs prior to access, needleless connectors, and injection ports; dressing changes with CHG-impregnated dressings every 5-7 days or sooner if visibly soiled, wet, or loose; use of antibiotic-impregnated catheters; and use of ethanol-impregnated disinfection caps [17-22].

Compliance with central line insertion and maintenance bundles is associated with lower CLABSI rates [23-25]. In order to ensure CVC bundled care, compliance is sustained on a patient, unit, and health system level; audit and reminders of bundle elements may increase consistency and subsequently reduce the risk of bloodstream infection [26].

Bundled CVC care has been shown to reduce CLABSI rates in transplant recipients as well. Implementation of process improvement strategies including standardization, monitoring with feedback, and plan-do-study-act cycles contributed to a $61 \%$ decrease $(4.2-1.8$ per 1000 CVC days) in a liver transplant ICU [14]. Implementation of a CVC maintenance bundle resulted in a significant CLABSI reduction in pediatric HSCT patients [27]. Identification of drivers for a rising CLABSI rate in a pediatric hematology-oncology unit and rapid development of interventions, such as identification of patients at high risk for CLABSI and involvement of senior nurses to assist less experienced nurses in dressing changes, resulted in a CLABSI rate reduction from 2.03 to 0.39 per $1000 \mathrm{CVC}$ days [12]. 


\section{Catheter-Associated Urinary Tract Infections}

Catheter-associated urinary tract infection (CAUTI) is a common HAI, resulting in increased cost [8] and increased length of stay [28]. Like CLABSI, CAUTI are largely preventable. The greatest risk factor for CAUTI is prolonged duration of indwelling urinary catheterization. Urinary catheters are often placed unnecessarily and remain in place longer than needed. Prevention measures include limiting insertion of indwelling urinary catheters, use of aseptic technique for insertion by a trained provider, regular perineal care, maintaining unobstructed flow of urine, and removal of the catheter as soon as it is no longer necessary.

CAUTI disproportionately affect solid organ transplant (SOT) recipients, with the most data available for kidney transplant recipients. In an analysis of kidney transplant recipients in the United States from 2002 to 2012, 7.5\% of kidney transplant recipients developed CAUTI [29]. Patient-specific risk factors for CAUTI in kidney transplant include age, female sex, and pre-transplant loss of function. Several studies confirm that prolonged duration of indwelling urinary catheter in kidney transplant recipients is a risk factor for both CAUTI and bacteremia [30-32].

Hospitals can reduce urinary catheter utilization by developing and implementing criteria for acceptable indications for indwelling urinary catheter use, such as when there is acute urinary obstruction, to assist in healing of pressure ulcers, or for select surgical procedures like kidney transplantation [33]. There are several approaches to facilitate compliance with facility-specific utilization guidelines. A nurse-led approach incorporating multidisciplinary rounds on inpatient units that focused on appropriate indications for insertion and timely removal of urinary catheters was effective in reducing the number of catheter days on several units [34]. Reminders for indwelling urinary catheter removal and stop orders embedded within the electronic health record have been effective in decreasing catheter use and significantly reducing CAUTI rates in multiple studies [35]. Since limiting duration of urinary catheters is recommended, the risk of early catheter removal in kidney transplant must be balanced with the potential risk of perioperative urologic complications. The optimal duration of catheterization in this population remains controversial; however early removal should be considered in the appropriate patient $[36,37]$. A multidisciplinary team focused on CAUTI-prevention education of nurses and other clinical staff led to a reduction in the CAUTI rate in the transplant care unit where rates had been higher than in the general hospital population [38].

There are no specific differences in the recommendations for maintenance of indwelling urinary catheters in transplant recipients compared with other patient populations. The Centers for Disease Control and Prevention (CDC) recommends use of aseptic technique with sterile equipment for urinary catheter insertion [39]. In a recent randomized controlled trial in Australia, use of chlorhexidine solution for meatal cleaning at the time of catheter insertion resulted in a decreased incidence of CAUTI compared with use of sterile saline [40]. For maintenance after insertion, however, meatal care with antiseptic solutions has shown no demonstrable benefit over routine perineal hygiene [41]. 
In addition to routine hygiene, maintenance efforts to reduce CAUTI focus on ensuring unobstructed flow of urine. Preventing kinking in catheter tubing allows for free flow of urine from the urethra to the collection bag. Lastly, keeping the collection bag below the level of the bladder and regular emptying of the collection bag prevent reflux of urine from the unsterile bag to the urethra [39]. Involving ancillary HCP (e.g., transporters and physical therapists) in an interdisciplinary promotion of urinary catheter maintenance is important as all members of the healthcare team may be involved in the maintenance of necessary urinary catheters [42].

\section{Clostridioides difficile}

Clostridioides difficile infection (CDI) causes a spectrum of disease ranging from asymptomatic colonization or diarrhea due to mild infection to ileus, megacolon, bowel perforation, and septic shock. It is the most common HAI and poses unique infection control risks due to the environmental persistence of infectious spores.

Risk factors for CDI include frequent contact with healthcare settings, receipt of antimicrobials, hospitalization on inpatient units with high rates of overall antimicrobial use [43], immune compromise, poor hand hygiene compliance, and lapses in environmental disinfection. Thus it is not surprising that SOT and HSCT recipients have significantly higher rates of CDI than do general medical or surgical inpatients $[44,45]$.

Up to $29 \%$ of hospitalized patients are colonized with $C$. difficile [46]. This colonization rate may be higher in HSCT patients and is not well described in SOT recipients [47]. Patients who are colonized are more likely to subsequently develop symptomatic CDI [48]. Antimicrobial stewardship, hand hygiene, and environmental disinfection are important strategies to reduce rates of both symptomatic infection and transmission.

Recommended commercial testing modalities for $C$. difficile include a stool toxin test as part of a multistep algorithm or nucleic acid amplification test (NAAT) alone. There are drawbacks to each type of test; two- or three-step algorithms that include a stool toxin test have relatively low sensitivity, while NAAT without patient-specific symptoms to guide testing does not differentiate between colonization and symptomatic disease. Diagnostic testing should be considered in patients with three or more unformed stools in $24 \mathrm{~h}$ or less, who have not had prior testing within the preceding 7 days and who do not have alternative causes of diarrhea, such as laxative use. Testing of asymptomatic patients is not recommended [49], and there are no recommendations to use contact precautions for patients who are asymptomatically colonized. Test of cure should not be performed to guide either treatment duration or cessation of transmission-based precautions.

For patients with diarrhea, contact precautions including gowns and gloves should be initiated preemptively pending $C$. difficile test results and continued if positive until $48 \mathrm{~h}$ after diarrhea resolution to prevent transmission to other patients from HCP hands, clothing, and mobile medical equipment. It is preferable to have 
patients with CDI in single-patient rooms with separate toileting facilities. In the setting of space limitations, incontinent patients should be prioritized for singlepatient rooms. If cohorting is required, patients with the same strain of CDI (e.g., two patients with the $C$. difficile B1/NAP1/027 strain) rather than different strains can be cohorted [49]. This information, however, may not be readily available. Shedding of C. difficile spores in the stool may be prolonged even after symptom resolution. In centers where there are high rates of CDI, maintaining contact precautions until discharge may be warranted.

Use of ABHR or handwashing with soap and water is recommended when caring for patients with CDI. Compliance with ABHR is higher than with traditional handwashing; however ABHR is not sporicidal and thus may pose a higher risk of transmission of $C$. difficile spores despite good compliance. In settings where there are outbreaks or sustained high rates of CDI, hand hygiene with soap and water is preferred.

Bleach or other sporicidal surface disinfectants are needed to eliminate environmental persistence of spores. Daily and terminal room cleaning with a sporicidal agent may help reduce the risk of transmission of $C$. difficile to patients, especially when there are high baseline rates of CDI [49]. The addition of ultraviolet light terminal disinfection may reduce the risk of $C$. difficile transmission, although studies have shown mixed results [50,51]. Despite environmental disinfection interventions that result in objective measures of improved environmental cleaning, a multicenter randomized study found no effect of this on the incidence of healthcare-associated CDI [52]. This highlights that there are many other important factors that affect the incidence of CDI, including pre-existing $C$. difficile asymptomatic colonization, antimicrobial use and overuse, testing stewardship, hand hygiene, disinfection of shared mobile medical devices, and compliance with contact precautions.

\section{Surgical Site Infections}

Despite improvements in perioperative management, surgical site infections (SSIs) continue to threaten SOT recipients early after transplantation. Healthcare and antimicrobial exposures are ubiquitous in SOT, and with increased wait times, there is a parallel increased risk for MDROs. The highest rates of SSI are reported in intestinal and multivisceral abdominal organ transplants [53].

Evidence-based strategies aimed toward SSI reduction in the general surgical population can be applied to SOT [54]. These include close attention to maintenance of sterility, surgical technique, minimizing operative time, and minimizing transfusion requirements. The role of the anesthesiologist has been defined and includes reducing environmental contamination, catheter and airway management, as well as perioperative temperature, oxygenation, and glycemic management [54, 55]. Organ-specific risk factors for SSI have been recently reviewed [53].

In centers with increased incidence of $S$. aureus infections, there may be a role for active surveillance and decolonization with mupirocin and/or CHG. Decrease 
in $S$. aureus SSIs has been demonstrated in cardiac and lower joint surgeries when decolonization is included as part of a care bundle [56]. Although not specific to SSI prevention, predictive models suggest utility in thoracic transplantation with the goal of decreasing posttransplant $S$. aureus infections [57]. Decolonization of SOT candidates can be problematic as durability is incomplete [58], and unless a live donor is available, the timing of transplant remains unpredictable.

Perioperative antimicrobial selection should be determined by the transplanted organ. Preferred antimicrobial regimens tend to be heterogeneous and transplant center-specific [59]. Organ-specific risk factors may require modification or augmentation of regimens (i.e., addition of antifungal prophylaxis) [53]. Although not systematically studied, alteration in prophylaxis based on donor and recipient microbiology as well as institutional antibiograms is likely warranted. Societal recommendations for dosage, including weight-based dosing, and timing including re-dosing are applicable [60]. Extended durations are rarely warranted and should be discouraged.

Recently, the need for patient engagement in HAI prevention has been highlighted [61]. The role of the patient and caregiver may be paramount in SSI prevention [62]. Smoking cessation, diabetes management, and hygiene including compliance with hand hygiene and bathing can influence infection risk. Both patients and their caregivers should be encouraged to promote HCP hand hygiene and appropriate wound care. In addition, educating patients about signs and symptoms of infection can prompt early identification of potential SSIs that may prevent morbidity.

\section{Preventing Infections Associated with the Healthcare Environment}

Transplant recipients are not only at risk for the same wide variety of infections that affect patients with intact immune systems; they are also at a unique risk for infections related to bacteria, mycobacteria, and molds found in the healthcare environment. While HSCT guidelines outline specific infection prevention and control practices [13], there are no standard infection prevention and control strategies among SOT programs [63]. Limiting exposure to environmental molds, such as Aspergillus, and water-related opportunistic pathogens, such as Legionella species and nontuberculous mycobacteria (NTM), should be a focus of infection prevention and control efforts in the healthcare settings. In addition, access to molecular typing may aid in the identification of potential sources and inform mitigation strategies.

\section{Environmental Mold}

Nosocomial mold infections among transplant recipients result from respiratory exposure to fungal spores. Air and water can be sources of pathogenic fungi. Opportunistic molds such as Aspergillus and Fusarium can be present in a hospital's 
water supply and may be ingested or inhaled when in water droplets formed from hospital showers or sinks. Water damage to sheetrock from leaks can lead to mold growth and subsequent aerosolization of mold spores within the hospital. Plants, unwashed fruits and vegetables, and fresh or dried flowers can harbor Aspergillus. Elevator shafts may pose an additional risk, as shaft surfaces are hard to clean, air moving within the shaft can harbor mold spores, and patients may be exposed during transit within the hospital.

There have been several published reports of environmental mold infections in immune-compromised patients, including transplant recipients, related to hospital linens. Outbreaks of Rhizopus have been linked to hospital linens that have been washed in low temperatures, stored in humid and/or dusty conditions, or stored in bins exposed to dust $[64,65]$. Facilities supplying linens to the healthcare setting should wash, store, and transport linens in a clean environment, use high wash temperatures, and ensure linens are completely dry prior to packaging. Hospitals should prevent dust contamination of linens during transport, keep linen storage bins clean, and not top off linens prior to patient use (first in, first out premise) [66].

Hospitalized HSCT recipients should be placed in protective environment (PE) rooms [13, 67]. Use of PE rooms for SOT recipients, including lung transplant recipients, is variable among transplant centers [63]. PE rooms are designed to protect severely immune-compromised patients from human and environmental airborne pathogens. These rooms have positive air pressure in relation to the hallway, with high-efficiency particulate air (HEPA) filtration to remove particles $\geq 0.3 \mu \mathrm{m}$ in diameter that can pose an infectious risk and $\geq 12$ air exchanges per hour to bring in fresh air and remove stale air. In a tertiary care hospital setting, patients with HSCT or hematologic malignancy who had significant exposure outside of the PE room during their hospitalization had higher risk for invasive mold infections [68].

The differential in air pressure should be monitored continuously, ideally by automated systems that alert appropriate staff when the pressure difference is lost. In order to prevent air containing spores from outside the room getting in, and to maintain positive pressure, PE rooms should be sealed, with filling in of gaps between walls, floors, ceilings, windows, and doors [13].

Use of HEPA filtration is especially important when construction is conducted within or near the hospital. A heightened risk to immune-compromised patients comes from the aerosolization of mold spores during construction within or in proximity to a hospital, and outbreaks of healthcare-associated environmental mold infections have occurred in relation to adjacent construction in hospitalized immune-compromised patients [69].

Construction plans should include measures to control mold and should be made in conjunction with the hospital's infection prevention and control department, who can develop an infection control risk assessment (ICRA). ICRAs in this scenario focus on measures to control and minimize airborne dissemination of fungal spores, such as resealing of hospital windows, use of portable HEPA filters in rooms of susceptible patients, use of $\mathrm{N} 95$ particulate respirators for patients during travel 
within and outside of the hospital, and planning for staff caring for susceptible patients to enter and exit the hospital away from the site of construction $[66,70]$.

Due to multiple potential environmental sources, hospitals should perform surveillance for healthcare-associated mold infections particularly during and after construction events and in highly susceptible patients. This can include utilization of the electronic health record or surveillance software to identify patients with radiographic changes consistent with invasive mold infections; regular review of microbiology laboratory reports for growth of Aspergillus and other opportunistic molds; monitoring of therapeutic antifungal use; and location tracing of infected patients to identify high-risk environmental exposures [71]. Additionally, scheduled environmental assessments for water damage and dust, and environmental sampling for identification of mold, can be used to target mitigation efforts [66].

\section{Waterborne Pathogens}

In addition to invasive mold infections, transplant recipients and other immunecompromised patients are at higher risk for infections due to waterborne pathogens. The hospital water supply is increasingly identified as a source of nosocomial acquisition [72], likely related to the size and complexity of healthcare facility water systems and the vulnerability of patients treated in these facilities. Outbreaks of infections related to water exposure within a hospital have included Legionella species, nontuberculous mycobacteria, Pseudomonas aeruginosa, and other Gramnegative bacteria. These organisms are often referred to as opportunistic premise plumbing pathogens (OPPP). Sources identified in outbreak investigations include potable water, sinks, aerators, showers, immersion tubs, ice and ice machines, and decorative fountains. Transmission of pathogens occurs through both direct and indirect contacts, ingestion, aspiration, and/or aerosolization.

Legionella, atypical mycobacteria, as well as Pseudomonas aeruginosa and other Gram-negative bacteria are normal inhabitants of drinking water. These bacteria may be chlorine- and heat-resistant and can form biofilms on plumbing surfaces, making them difficult to eradicate from a hospital's water supply once detected [73]. Older water systems can promote stagnation, corrosion, and the biofilm formation, thus propagating the growth of OPPP.

Water management programs targeting conditions conducive to growth of Legionella and other OPPP can reduce their growth in water and prevent transmission to susceptible patients. Mitigation strategies (Table 1) for potential sources have been previously published [72]. Copper-silver ionization of water is one disinfection method used by healthcare facilities to control growth of Legionella spp.; it reduces the risk of Legionella positivity in environmental samples, and it may have effects on Pseudomonas and other Gram-negative bacteria by binding to bacterial cell walls and destroying biofilms that can harbor bacteria [74, 75]. Monochloramine, a combination of chlorine and ammonia, is also used to limit growth of Legionella and other opportunistic pathogens in hospital water supplies [76]. However, neither disinfection system is perfect. Legionella may still be detected in hospital water 
Table 1 Healthcare-associated reservoirs for opportunistic premise plumbing pathogens and potential risk mitigation strategies in the setting of healthcare-associated cases or isolation of potential pathogens during routine sampling

\begin{tabular}{|c|c|c|}
\hline Reservoir & Potential pathogens & Mitigation strategies for high-risk units \\
\hline $\begin{array}{l}\text { Potable } \\
\text { (tap) water }\end{array}$ & $\begin{array}{l}\text { Legionella species } \\
\text { Pseudomonas aeruginosa } \\
\text { Gram-negative bacteria } \\
\text { Nontuberculous } \\
\text { mycobacteria }\end{array}$ & $\begin{array}{l}\text { Ensure that semicritical devices including } \\
\text { respiratory devices are not rinsed in tap water (use } \\
\text { sterile water) } \\
\text { During water disruptions refrain from using or } \\
\text { drinking tap water (e.g., showering, rinsing, or } \\
\text { ingesting) } \\
\text { Periodic sampling of water for Legionella spp. } \\
\text { especially in high-risk units including organ } \\
\text { transplant units and hematopoietic stem cell } \\
\text { transplant units } \\
\text { Remove aerators or develop an appropriate } \\
\text { maintenance and disinfection plan for high-risk } \\
\text { units especially in the setting of detected Legionella } \\
\text { spp. in water samples or evidence of hospital-onset } \\
\text { disease } \\
\text { Discourage automated faucets due to the inability to } \\
\text { achieve high outlet temperatures and inability to } \\
\text { flush } \\
\text { Discourage decorative water features (e.g., } \\
\text { fountains) } \\
\text { Discourage showers or develop an appropriate } \\
\text { maintenance and disinfection plan of shower heads } \\
\text { If basins are used for bathing, a plan should be in } \\
\text { place for disinfection of basins or the basins should } \\
\text { not be reused } \\
\text { Potential disinfection methods include copper } \\
\text { ionization, hyperchlorination, superheating, and } \\
\text { filtration - a water management plan should be in } \\
\text { place and reviewed periodically with infection } \\
\text { prevention and control and facilities experts } \\
\text { Heighten awareness and surveillance for } \\
\text { legionellosis, unusual nontuberculous } \\
\text { mycobacterial infections, and increased incidence of } \\
\text { hospital-onset respiratory infections with Gram- } \\
\text { negative bacteria }\end{array}$ \\
\hline Sinks & $\begin{array}{l}\text { Gram-negative bacteria } \\
\text { including carbapenem- } \\
\text { resistant } \\
\text { Enterobacteriaceae }\end{array}$ & $\begin{array}{l}\text { Ensure separation of handwashing sinks from sinks } \\
\text { where contaminated waste may be disposed (e.g., } \\
\text { hopper or utility sink) } \\
\text { Ensure a maintenance and disinfection plans for } \\
\text { sinks (including drains) located in patient rooms } \\
\text { where aerosolization or splashing may occur }\end{array}$ \\
\hline $\begin{array}{l}\text { Heater- } \\
\text { cooler } \\
\text { devices }\end{array}$ & $\begin{array}{l}\text { Legionella } \text { species } \\
\text { Pseudomonas aeruginosa } \\
\text { Gram-negative bacteria } \\
\text { Nontuberculous } \\
\text { mycobacteria }\end{array}$ & $\begin{array}{l}\text { Ensure that maintenance and disinfection are } \\
\text { occurring as per manufacturer's instructions } \\
\text { Heighten awareness and surveillance for } \\
\text { nontuberculous mycobacteria after cardiac surgery } \\
\text { including transplant } \\
\text { Position the device to allow vent to exhaust away } \\
\text { from the surgical field }\end{array}$ \\
\hline
\end{tabular}


systems despite use of copper-silver ionization [77], and there is the potential for an increase in detection of mycobacteria in water systems with use of monochloramine disinfection [78].

Plumbing design to limit dead-end pipes and subsequent water stagnation can help limit OPPP overgrowth [66]. Other interventions include use of reverse osmosis filters on faucets and shower heads, maintaining circulating water at high temperatures with addition of cold water at the point of use (sinks, showers), or periodic superheating of the water system to limit bacterial growth in circulation [79, 80].

Legionella pneumophila and other Legionella species are opportunistic pathogens that can cause a life-threatening pneumonia in susceptible patients. Transmission occurs via inhalation of aerosols and can come from showers, faucets, or cooling towers in the community or healthcare setting. An outbreak of $L$. pneumophila serotype 3 among HSCT patients in a new bone marrow transplant unit in an Israeli hospital was linked to heavy contamination of potable water with the same serotype [81]. Interventions implemented included restrictions on drinking tap water and showers for HSCT patients, in addition to superheating and hyperchlorination of the water system. An outbreak of Legionella micdadei pneumonia among kidney and heart transplant recipients at a US hospital was linked molecularly to L. micdadei isolated from hot water sources, including showers and sinks in patient rooms and the hospital-wide hot water recirculation loop [82]. Mitigation strategies included superheating and subsequent chlorination of the water system. Legionella outbreaks have also been linked to decorative water fountains in the healthcare setting [77, 83]. Mortality from Legionnaire's disease is $25 \%$ based on national surveillance data; however rates specific to transplant recipients are not known [84].

Nontuberculous mycobacteria can be found in soil, water, and dust, and these environmental sources can lead to community-acquired or nosocomial infection. NTM have been linked to multiple outbreaks in healthcare settings, often related to the hospital or municipal water supply. One such outbreak occurred among pediatric HSCT patients after the opening of a new hospital building. An increase in isolation of the rapidly growing mycobacteria $M$. chelonae from clinical cultures was traced to the new building's water supply. Water samples collected from hospital faucets, showers, and ice grew M. chelonae and other NTM. Infection prevention and control efforts included use of only bottled water for consumption in HSCT patients and reinforcement of a policy to run showers for 2 minutes prior to patients entering to reduce the mycobacteria density in water [85]. This policy had been put in place several years earlier in response to an outbreak of M. mucogenicum bacteremia linked to exposure of patients with central venous catheters to M. mucogenicumcontaminated shower water [86].

Another US hospital noted an increase in the incidence of M. abscessus isolated from respiratory sample cultures after opening a new hospital building, disproportionately affecting lung transplant recipients [87]. Environmental cultures from biofilms of water sources in the hospital addition grew M. abscessus, and it was hypothesized that micro aspirations from tap water led to lung colonization and subsequent infection. Interventions to prevent and control further exposure to $M$. 
abscessus included use of sterile water instead of tap water for oral care, respiratory therapy, consumption, and enteral tube flushes for all lung and heart transplant recipients, ICU patients, and patients with disrupted GI tracts [87]. The authors noted that low flow rates in the hospital addition's water distribution system, put in place to conserve water, may have facilitated higher water concentrations of $M$. abscessus.

Disseminated NTM infections, specifically $M$. chimaera, have been associated with the use of extracorporeal circulation in cardiac surgeries [88]. These heatercooler devices (HCDs) are used ubiquitously in heart transplantation. Identification of the potential for these devices to aerosolize NTM as well as other waterborne pathogens led to several control efforts. These included revisions and a request for adherence to the manufacturers' instructions for maintenance and disinfection of these devices; use of sterile or filtered water; and positioning the device in order to vent to exhaust away from the operative field. Although not previously routine practice, NTM should be considered in the differential diagnoses of otherwise unexplained infections in patients after cardiac surgery including SSI. Legionellosis and infections with Gram-negative bacteria have also been linked to HCDs.

An outbreak of Pseudomonas fluorescens-related febrile neutropenia in HSCT recipients was linked by molecular typing to a contaminated drinking water dispenser in a hospital in the United Kingdom. This hospital performed routine weekly pharyngeal screening for Pseudomonas carriage at baseline in hematology patients, allowing for identification of pharyngeal colonization in the absence of other positive clinical cultures [89]. A hospital in Finland used pulsed-field gel electrophoresis to link 11 cases of Pseudomonas aeruginosa bacteremia in HSCT recipients to isolates from showers and sinks with the same PFGE pattern in their bone marrow transplant unit [90]. No further cases of Pseudomonas aeruginosa infection with the same PFGE pattern occurred after implementation of infection control measures, which included hand disinfection, disinfection of shower pipes and shower heads, and use of hot water when cleaning. Similarly, other outbreaks due to other multidrug-resistant Gram-negative bacteria including carbapenemresistant Enterobacteriaceae (CRE) have been linked to contaminated sinks using molecular typing including whole genome sequencing [91-93]. Separating handwashing sinks from areas used for disposal of contaminated waste and disinfection and/or reconfiguration of existing pipes or water systems are important strategies to address identified risks.

Similar to surveillance for other HAI such as CLABSI or CAUTI, use of the electronic health record to identify patients with nosocomial pneumonia can guide targeted interventions, such as testing for Legionella infection and other waterborne opportunistic pathogens in susceptible patients. Additionally, targeted environmental surveillance that includes culture of the hospital water supply in areas housing high-risk patients can identify the affected areas and guide eradication efforts [77]. Special attention should be given to the performance of institutional hazard analyses and revisions of water management plans to ensure ongoing attention to the potential environmental risk to transplant populations and other susceptible hosts. 


\section{Colonization with Multidrug-Resistant Organisms}

Multidrug-resistant organisms (MDROs) include methicillin-resistant Staphylococcus aureus (MRSA), vancomycin-resistant enterococci (VRE), and Gram-negative organisms including extended-spectrum $\beta$-lactamase (ESBL) or CRE. Candida auris, an emerging healthcare-associated yeast, is also considered a MDRO because of its antifungal resistance profiles, its unique ability to colonize the skin, and its persistence in the healthcare environment [94].

Enterococci are gastrointestinal common commensals. Gastrointestinal VRE carriage is the major reservoir of the organism in the healthcare setting. VRE can survive on surfaces, and transmission can occur via healthcare workers, mobile medical equipment, or shared toileting facilities [95]. Similar to VRE, ESBLproducing and carbapenem-resistant Gram-negative bacteria can persist through gastrointestinal carriage.

Like VRE and multidrug-resistant Gram-negative organisms, patients tend to be the reservoir for transmission of $S$. aureus. S. aureus colonizes the nares and skin in up to $30 \%$ of healthy people. Patients with MRSA colonization are more likely to develop MRSA bacteremia than patients who are not colonized [96, 97]. Nosocomial MRSA infections are often associated with breaks in skin and mucosal barriers including intravascular catheters, endotracheal tubes, or recent surgery and confer significant morbidity and mortality risk $[98,99]$. The epidemiology of MRSA in organ transplantation has recently been reviewed [100].

The prevalence of MDRO in the healthcare setting has increased globally over the last several decades [101-103]. In data reported to the CDC's National Healthcare Safety Network, MRSA and VRE are the most commonly identified MDRO associated with device-related infections or SSI [104, 105]. SOT recipients in particular have a high prevalence of CRE [106-109], and VRE colonization is common in HSCT recipients [110] and organ transplant candidates and recipients [95]. In terms of CRE risk, international travel and healthcare exposures including SOT and HSCT in other countries may potentially introduce novel mechanisms of resistance to transplant units [109].

Risk factors for MDRO acquisition are ubiquitous in transplantation. These include high rates of antimicrobial use for both prophylaxis and treatment, frequent and/or prolonged hospitalizations, invasive procedures, high device utilization rates, and medical comorbidities such as kidney failure [100].

As with MRSA, MDRO colonization often precedes invasive disease. In the setting of active surveillance, liver transplant candidates and recipients with asymptomatic MRSA or VRE colonization were at increased risk for invasive MRSA or VRE infection, respectively, when compared with patients who were not colonized, and VRE colonization was associated with an increased risk of mortality [111]. A meta-analysis of 23 studies looking at the effect of MRSA and VRE colonization in liver and other SOT recipients found a similarly increased risk of infection with colonization in the pre- and posttransplant periods [112]. Additionally, a prospective study of liver transplant recipients with active surveillance for rectal MDRO colonization found that even intermittent colonization was significantly associated with 
subsequent MDRO infection [113]. In a retrospective study of liver recipients, carbapenem-resistant Klebsiella pneumoniae colonization was a significant risk factor for invasive carbapenem-resistant $K$. pneumoniae [114].

Interventions such as antimicrobial stewardship; monitoring of environmental disinfection - including disinfection of mobile medical equipment - monitoring of hand hygiene compliance; active surveillance; antiseptics applied to the skin, nares, and oral mucous membranes; and standard and contact precautions can help reduce MDRO colonization and prevent transmission to other patients [115]. Measures to lower the risk of invasive infection include the instating and monitoring compliance with the aforementioned evidence-based bundles to insert and maintain vascular and urinary catheters and oral care and ventilator management to prevent lower respiratory tract infections in ventilated patients.

The CDC and European guidelines recommend the use of standard and contact precaution for patients with MDRO colonization or infection [115-117]. In select settings the role of contact precautions and the duration of contact precautions may require reexamination especially for ESBL producers [109, 118], MRSA and VRE. Two large trials found these precautions were no more effective than standard precautions in reducing MRSA or VRE transmission [119, 120]. A systematic review and meta-analysis of 14 studies found that discontinuing contact precautions for MRSA and VRE did not lead to increased infection rates [121]. An additional meta-analysis of nine studies looking at infection prevention and control measures to reduce transmission of VRE found that improved hand hygiene compliance, but not contact precautions, decreased the VRE transmission rate [122]. Additionally, contact precautions are associated with fewer bedside visits from healthcare personnel and more preventable adverse events [123]. In the setting of outbreaks, the use of contact precautions may be warranted [124].

Active surveillance for MDROs in asymptomatic patients can identify patients at higher risk for invasive infection and facilitate targeted interventions, such as skin and mucous membrane antisepsis to reduce MDRO colonization or broader empiric antimicrobial management for sepsis. Recent publications have shown that active surveillance with implementation of standard plus contact precautions for carbapenem-resistant Enterobacteriaceae (CRE) reduces CRE colonization and infection $[125,126]$. However, there is a lack of strong evidence that universal screening for CRE in asymptomatic pre- and posttransplant recipients is of benefit [127].

In a multicenter cluster randomized trial, daily chlorhexidine bathing of patients in ICUs and HSCT units reduced the risk of MDRO acquisition and subsequent bloodstream infection [16]. A large cluster randomized trial of ICU patients in multiple hospitals found that universal decolonization with nasal mupirocin and CHG bathing and, to a lesser degree, targeted MRSA screening and decolonization were more effective than active MRSA surveillance with standard and contact precautions in reducing rates of MRSA colonization and bloodstream infection [128]. In a single center, active surveillance for MRSA colonization in liver transplant recipients with targeted infection control interventions (i.e., contact 
precautions, cohorting, intranasal mupirocin for decolonization) reduced MRSA colonization and invasive infection [129].

\section{Respiratory Viruses}

Respiratory viral infections can contribute to significant morbidity in the immunecompromised host [130]. During periods of intense immunosuppression, early after transplantation or in the setting of GVHD, both SOT and HSCT recipients are at increased risk of viral infection-related complications. These potential complications include progression from upper respiratory tract infections to lower tract infections and pneumonia, bacterial and fungal superinfections, and respiratory failure [131]. In addition, respiratory viral infections have been associated with bronchiolitis obliterans in lung transplant recipients and long-term airflow decline in HSCT recipients.

Molecular diagnostic platforms provide both rapid and accurate results and should be utilized early. Staff should be encouraged to adhere to standard precautions including hand hygiene, disinfection of shared equipment, and respiratory hygiene and cough etiquette. Due to the high rates of morbidity observed in HSCT recipients, some centers recommend universal masking either year-round or during periods of increased community activity of respiratory syncytial virus (RSV) or influenza [132]. Systematic evaluations have not been performed supporting universal masking, and controversy exists regarding the preferred mask [133, 134]. Moreover, contact precautions (use of gowns and gloves) are recommended for some respiratory viruses in addition to standard precautions [115].

Persistent and asymptomatic viral shedding is common in immunosuppressed populations [131]. Thus, defining the optimal duration of transmission-based precautions in the inpatient setting is difficult, and variability exists between centers.

\section{Influenza}

Although traditionally influenza season commences in the Fall and can persist well into Spring, novel influenza viruses with pandemic potential may emerge at any time. Indeed, many lessons were learned in 2009 with the emergence of H1N1 in both the community and healthcare settings $[135,136]$.

Nosocomial acquisition and healthcare-associated outbreaks among transplant recipients (both SOT and HSCT) have been reported. In general, an outbreak investigation is initiated in the setting of a single hospital-onset case. Updated guidance regarding outbreak control is available and is applicable to both the SOT and HSCT patients [137]. In order to avoid nosocomial and/or sustained transmission, institutions are recommended to encourage vaccination, screen for symptoms, 
emphasize appropriate patient placement and early diagnostics, initiate early treatment, and establish a procedure for addressing ill healthcare personnel.

Annual vaccination with inactivated influenza vaccine for patients and household contacts is strongly encouraged. It is important to note that both antibody- and cell-mediated immune responses are likely suboptimal early posttransplantation [138]. However, vaccination of SOT and HSCT patients has been associated with improved outcomes [139]. Potential strategies to improve immune response in the SOT population include offering booster doses or high-dose vaccine [140, 141]. Current recommendations include initiating annual influenza vaccine 6 months after HSCT. In the setting of increased community activity, vaccination can be offered as early as 3-4 months after HSCT [138].

During influenza season aggressive symptom screening of HCP, patients, and visitors is recommended. Many institutions limit nonessential visitors and enforce visitor age restrictions on high-risk units (i.e., HSCT units). Patients and visitors should be educated regarding symptoms, respiratory hygiene, and cough etiquette, and ill visitors should be excluded.

Influenza is transmitted through large droplets generated through talking, coughing, and sneezing. Transmission can occur through indirect contact with a contaminated environment and inoculation of mucosal surfaces. Airborne transmission can also occur especially in the setting of aerosolizing procedures, but the superiority of using respirators over surgical masks has not been established [142]. Currently, in addition to standard precautions, droplet precautions are recommended to reduce the risk of transmission. Patients should be prioritized to a single room when influenza is suspected or confirmed. Cohorting of symptomatic cases based on strain type may be prudent; however cohorting strategies should be discussed with infection preventionists or public health authorities.

In the setting of sustained transmission, nonessential admissions should be delayed, and consideration should be given to redirecting new admissions. Patient transport and movement should be minimized. Symptom screening of staff should be performed daily, and ill staff should immediately mask and be removed from direct patient care. Current recommendations are to exclude these individuals from working with patients until afebrile for $24 \mathrm{~h}$ without antipyretics and no earlier than 5 days after illness onset. In the setting of HSCT, the CDC recommends work exclusion or temporary reassignment for as long as 7 days from symptom onset.

Chemoprophylaxis with a neuraminidase inhibitor (i.e., oseltamivir) should be offered to roommates and ward mates of patients with influenza, irrespective of vaccination status [137]. Monitoring and audit of both hand hygiene and environmental disinfection should be prioritized. Patients should be empirically treated when influenza is suspected pending diagnostic results [139]. HCP who are not vaccinated should be vaccinated and offered chemoprophylaxis for 2 weeks after vaccination. In the setting of antigenic drift of circulating virus from vaccine strains, chemoprophylaxis should be considered for all influenza-exposed HCP irrespective of vaccination status. 


\section{Respiratory Syncytial Virus}

Respiratory syncytial virus (RSV) has been associated with morbidity in both SOT and HSCT [143]. The incidence of nosocomial RSV infections often mirrors that of increased community activity. Frequently increased activity is seen during the Fall and early Winter. Transmission is due to direct inoculation of mucous membranes and inhalation of droplets or by indirect inoculation by fomites from a contaminated environment. Outbreaks have occurred in both inpatient and ambulatory settings [144].

Despite evidence of droplet transmission, the routine use of masks is controversial. There has not been conclusive evidence suggesting masks decrease transmission even in the setting of an outbreak. The conjunctiva and nasal mucosa are major portals of entry, and the addition of masks and eye protection should be considered as part of standard precautions if exposure to respiratory secretions is anticipated [115]. A recent systematic review suggested that eye protection was more effective at reducing transmission than the addition of a mask as part of a multiple component outbreak response [145]. Patients with known or suspected RSV should be prioritized for single-patient rooms and placed in contact precautions. Cohorting, if necessary, should be coordinated with an institution's infection prevention and control department.

In the absence of an effective vaccine or chemoprophylaxis, primary prevention of nosocomial transmission is paramount. Prophylaxis with palivizumab, a RSVspecific monoclonal antibody, is variable among surveyed SOT centers [146, 147]. The American Academy of Pediatrics offers guidance regarding the use of palivizumab in pediatric populations during RSV season [148-150]. Off-label use in adults in an outbreak setting has been described [151].

Like influenza, in the setting of an outbreak of RSV, aggressive screening of visitors, HCP, and patients should occur. Visitor limitations and age restrictions may be required. Cohorting of both patients and staff and restricting patient movement as well as augmented monitoring of hand hygiene and environmental disinfection are recommended. In addition, HCP and visitors are encouraged to practice respiratory and cough etiquette. Ill HCP should be immediately removed from patient care; however, the optimal duration of exclusion or reassignment remains unclear. It should be noted that often individuals can be asymptomatic and can serve as a source for ongoing transmission [144]. Active laboratory surveillance in the absence of symptoms cannot be categorically recommended but can be considered in settings of sustained transmission [144].

\section{Adenovirus}

Contrary to both RSV and influenza, adenovirus infections do not demonstrate seasonality [152]. In immunocompetent hosts adenovirus causes a variety of infections depending on serotype. Infections can range from the asymptomatic or mild upper respiratory tract infection to epidemic keratoconjunctivitis and gastroenteritis. 
More serious infections that more often plague the immune-compromised host include pneumonia, hepatitis, hemorrhagic cystitis, encephalitis, and disseminated disease $[153,154]$.

Adenovirus is transmitted through direct contact with a patient's environment or via fomites and respiratory secretions. Serotypes associated with gastroenteritis can be transmitted through the fecal-oral route. Adenovirus requires both contact and droplet precautions in addition to standard precautions. Due to prolonged shedding, it is recommended that patients remain in precautions for the duration of the hospitalization [115].

Like RSV, there are no proven prophylactic strategies to prevent adenovirus transmission in the setting of an outbreak. The strategies outlined for both influenza and RSV including symptom screening, visitor restriction, increased audit of hand hygiene, PPE compliance, and disinfection are recommended. Adenovirus can be quite tenacious, and evaluating the role of the environment and potentially contaminated shared equipment is vital in stemming a potential outbreak [155]. The live vaccine currently available only to US military recruits is contraindicated in SOT and HSCT.

\section{Other Respiratory Viruses}

Other respiratory viruses (Table 2) can cause morbidity in both SOT and HSCT recipients. Partnering with infectious diseases and infection prevention and control is vital to controlling and preventing outbreaks. Like RSV and adenovirus, there are no proven prophylactic measures available; thus adherence to standard and recommended transmission-based precautions is crucial. In the setting of nosocomial acquisition, a multicomponent approach to outbreak control is recommended.

\section{Varicella-Zoster Virus}

Varicella may be transmitted through direct contact with the rash or through airborne transmission during primary or disseminated infection. Additional transmissionbased precautions may be recommended for patients on minimal immunosuppression with uncomplicated dermatomal zoster that be covered; however standard precautions can be used once disseminated disease has been excluded. Patients with primary VZV or herpes zoster involving more than two adjacent dermatomes should be placed in airborne and contact precautions. Patients should remain in airborne and contact precautions until lesions are dry and crusted, which can take longer in the profoundly immune compromised.

The advent of the varicella zoster vaccine has been pivotal in the prevention of primary varicella infections (chickenpox), and the timing of vaccination in transplant candidates has been reviewed [140, 156, 157]. In HSCT, patients can be vaccinated if no longer on immunosuppression and if over 2 years from HSCT without evidence of GVHD [157, 158]. Household contacts should receive age-appropriate VZV 


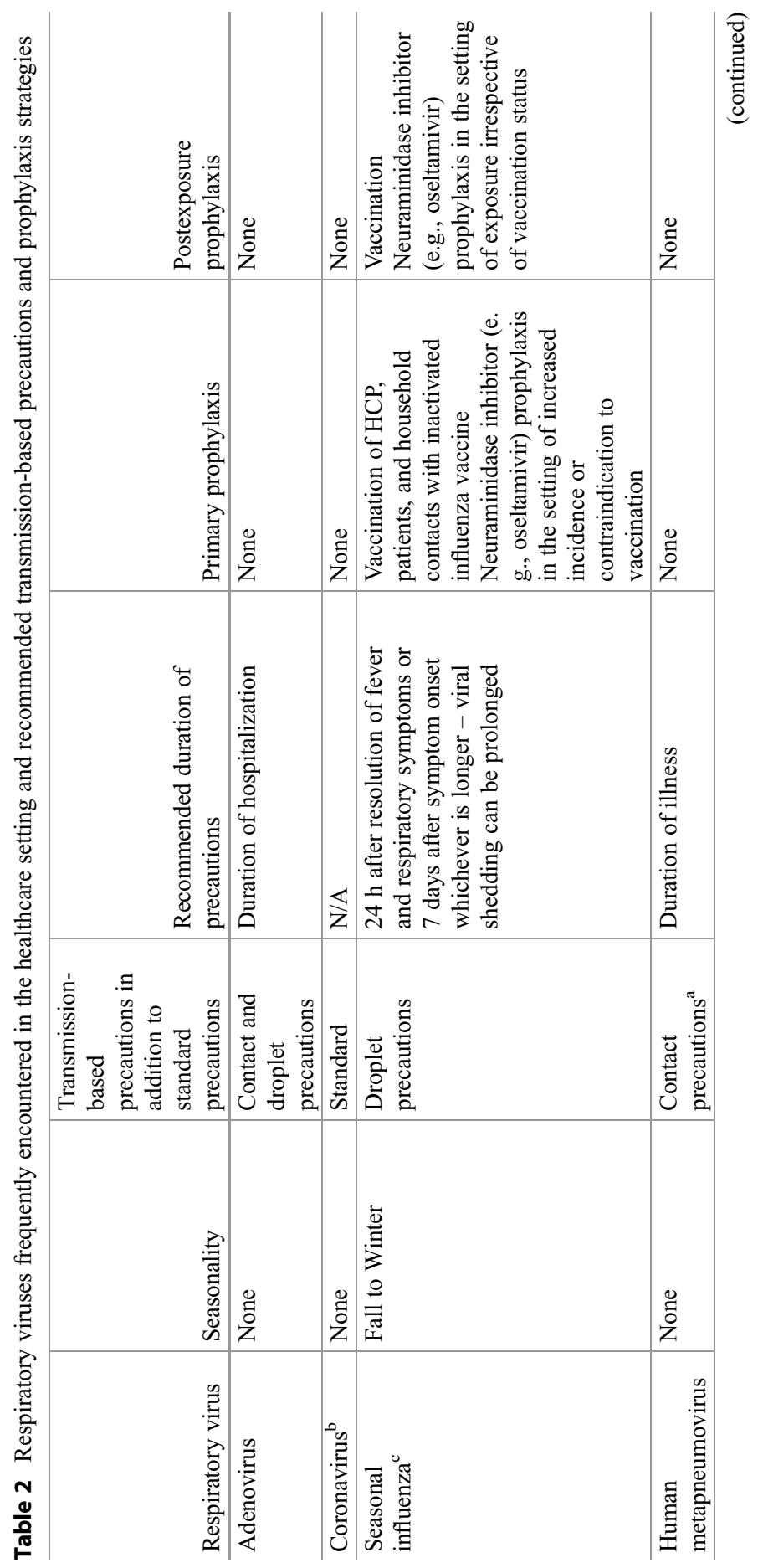




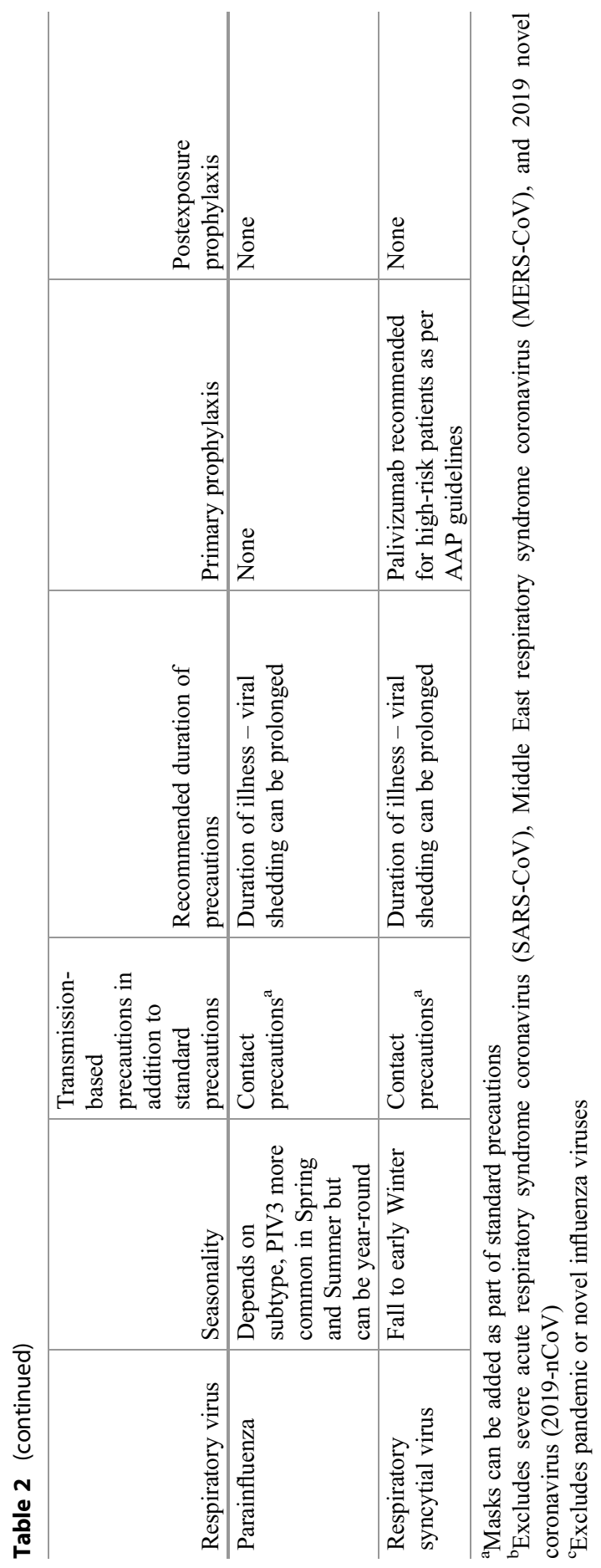


vaccinations. Transplant recipients should be isolated from contacts recently vaccinated with live-attenuated vaccines who develop a varicella-like rash. HCP are considered immune to VZV with laboratory confirmed immunity or written documentation of receipt of two doses of varicella vaccine [159].

In the setting of an exposure to varicella, nonimmune household contacts are encouraged to seek immunization. In terms of herpes zoster vaccination, household contacts should preferentially be offered the inactivated subunit vaccine rather than the live-attenuated vaccine. A categorical recommendation regarding subunit herpes zoster vaccine in SOT cannot be given at this time; however safety and efficacy data are emerging and trials are ongoing [140].

In the setting of nonimmunity, administration of Varicella zoster immune globulin (VZIG) within 10 days of an exposure is recommended [160]. Immunosuppressed patients with significant exposure may be required to furlough or be placed into airborne and contact precautions for 8-21 days postexposure. This period can extend to up to 28 days in the setting of receipt of VZIG. This recommendation is based on the average incubation of VZV being 2 weeks and transmission occurring 5-6 days prior to onset of the rash.

Use of antivirals for postexposure prophylaxis has not been systematically evaluated. It can be considered in the setting of patients unable to receive passive prophylaxis prior to 10 days postexposure. Current recommendations include a 7day course of acyclovir or valacyclovir beginning 7-10 days after exposure. Many recommend longer durations.

\section{Measles}

In 2018-2019, the resurgence of measles worldwide after eradication in many countries has led to a refocus on the prevention of measles in the healthcare setting $[161,162]$. Use of the live vaccine is contraindicated in SOT. In the setting of HSCT, vaccination is recommended in the absence of ongoing immunosuppression and GVHD. Current recommendations are to consider vaccination over 2 years from transplant. Irrespective of timing of SOT or HSCT, however, vaccination of household contacts is encouraged $[140,163]$.

Measles is highly contagious and requires immediate recognition and placement in airborne precautions. Patients are infectious 4 days prior to and 4 days after onset of the rash. The classic prodrome of cough, coryza, and conjunctivitis can be subtle and may be missed. In the setting of potential exposure and ongoing transmission, HCP should remain vigilant and err on the side of caution.

In the setting of an exposure where patients do not have documented immunity (defined as receipt of two doses of MMR vaccine or laboratory confirmation of immunity), transplant patients should receive immunoglobulin within 6 days of exposure [164]. In most cases patients with exposure who do not have evidence of immunity will be asked to quarantine with monitoring for symptoms for 21 days after exposure if no receipt of postexposure prophylaxis and 28 days after exposure with receipt of immunoglobulin. 
Outbreaks of measles have occurred within healthcare institutions involving both HCP and patients $[163,165,166]$. Currently HCP vaccination and assessment for immunity are recommended [159].

\section{Healthcare Personnel Vaccination}

HCP, like household contacts, are encouraged to receive all age-appropriate vaccinations including those where inactivated vaccines are not available. Currently, vaccination against influenza, varicella, measles, mumps, rubella, pertussis, and hepatitis $\mathrm{B}$ is recommended [159]. In the setting of inadvertent exposures to communicable diseases, healthcare providers should contact their institutional infection prevention and control department and occupation health providers in order to determine the role of prophylaxis, reassignment, or furlough in the case of documented nonimmunity and significant exposure.

\section{Conclusion}

Recommendations for infection prevention and control practices in the general inpatient and ambulatory population are applicable to both SOT and HSCT populations. It should be noted, however, that these populations do pose additional infection prevention challenges due to endogenous and exogenous immunosuppression, frequent exposure to healthcare, and antimicrobial exposures. Promotion of vaccination of patients, families, and HCP affords some protections from viruses and bacteria; however, vaccine hesitancy continues to exist in some communities. It is important for institutional leadership, transplant leadership, and infection prevention and control experts to partner and ensure that these unique populations are included in process improvement initiatives including those directed toward HAI prevention.

\section{Key Points}

- Hand hygiene compliance plays a pivotal role in preventing healthcare-associated infections.

- Care bundles and interdisciplinary teamwork have been associated with reduction in device-associated infections like central line-associated bloodstream infections and catheter-associated urinary tract infections in transplant patients.

- Transplant candidates and recipients are at increased risk for infections with environmental and waterborne pathogens, and mitigation strategies are available including patient placement, infection control risk assessments at the time of construction, and comprehensive water management plans.

- The use of molecular typing can aid in identifying the potential sources of outbreaks and inform mitigation strategies. 
- Vaccination of healthcare personnel, household contacts, and patients can prevent severe illness from communicable diseases like influenza and reemerging infections like measles.

\section{Cross-References}

Clostridioides difficile

Methicillin-Resistant Staphylococcus aureus

Nontuberculous Mycobacteria (NTM)

Respiratory Viral Infections

\section{References}

1. Graf K, Ott E, Wolny M, Tramp N, Vonberg RP, Haverich A, et al. Hand hygiene compliance in transplant and other special patient groups: an observational study. Am J Infect Control. 2013;41(6):503-8.

2. World Health Organization. WHO guidelines on hand hygiene in health care: first global patient safety challenge clean care is safer care. Geneva: WHO Guidelines Approved by the Guidelines Review Committee; 2009.

3. Ellison RT 3rd, Barysauskas CM, Rundensteiner EA, Wang D, Barton B. A prospective controlled trial of an electronic hand hygiene reminder system. Open Forum Infect Dis. 2015;2(4):ofv121.

4. Dyson J, Madeo M. Investigating the use of an electronic hand hygiene monitoring and prompt device: influence and acceptability. J Infect Prev. 2017;18(6):278-87.

5. Mody L, Washer LL, Kaye KS, Gibson K, Saint S, Reyes K, et al. Multidrug-resistant organisms in hospitals: what is on patient hands and in their rooms? Clin Infect Dis. 2019;67:1837-44.

6. Srigley JA, Furness CD, Gardam M. Measurement of patient hand hygiene in multiorgan transplant units using a novel technology: an observational study. Infect Control Hosp Epidemiol. 2014;35(11):1336-41.

7. Cheng VC, Chau PH, Lee WM, Ho SK, Lee DW, So SY, et al. Hand-touch contact assessment of high-touch and mutual-touch surfaces among healthcare workers, patients, and visitors. J Hosp Infect. 2015;90(3):220-5.

8. Zimlichman E, Henderson D, Tamir O, Franz C, Song P, Yamin CK, et al. Health careassociated infections: a meta-analysis of costs and financial impact on the US health care system. JAMA Intern Med. 2013;173(22):2039-46.

9. Ziegler MJ, Pellegrini DC, Safdar N. Attributable mortality of central line associated bloodstream infection: systematic review and meta-analysis. Infection. 2015;43(1):29-36.

10. Yetmar ZA, Lahr B, O’Horo J, Behfar A, Sampathkumar P, Beam E. Pulmonary artery catheter epidemiology of risk in pre-heart-transplant recipients. Infect Control Hosp Epidemiol. 2019;40(6):632-8.

11. Dandoy CE, Alonso PB. MBI-LCBI and CLABSI: more than scrubbing the line. Bone Marrow Transplant. 2019;54(12):1932-9. https://doi.org/10.1038/s41409-019-0489-1. Epub $2019 \mathrm{Feb} 26$.

12. Dandoy CE, Hausfeld J, Flesch L, Hawkins D, Demmel K, Best D, et al. Rapid cycle development of a multifactorial intervention achieved sustained reductions in central lineassociated bloodstream infections in haematology oncology units at a children's hospital: a time series analysis. BMJ Qual Saf. 2016;25(8):633-43. 
13. Tomblyn M, Chiller T, Einsele H, Gress R, Sepkowitz K, Storek J, et al. Guidelines for preventing infectious complications among hematopoietic cell transplantation recipients: a global perspective. Biol Blood Marrow Transplant. 2009;15(10):1143-238.

14. Russell TA, Fritschel E, Do J, Donovan M, Keckeisen M, Agopian VG, et al. Minimizing central line-associated bloodstream infections in a high-acuity liver transplant intensive care unit. Am J Infect Control. 2019;47(3):305-12.

15. Pronovost P, Needham D, Berenholtz S, Sinopoli D, Chu H, Cosgrove S, et al. An intervention to decrease catheter-related bloodstream infections in the ICU. $N$ Engl $\mathrm{J}$ Med. 2006;355(26):2725-32.

16. Climo MW, Yokoe DS, Warren DK, Perl TM, Bolon M, Herwaldt LA, et al. Effect of daily chlorhexidine bathing on hospital-acquired infection. N Engl J Med. 2013;368(6):533-42.

17. Marschall J, Mermel LA, Fakih M, Hadaway L, Kallen A, O'Grady NP, et al. Strategies to prevent central line-associated bloodstream infections in acute care hospitals: 2014 update. Infect Control Hosp Epidemiol. 2014;35(Suppl 2):S89-107.

18. Kagan E, Salgado CD, Banks AL, Marculescu CE, Cantey JR. Peripherally inserted central catheter-associated bloodstream infection: risk factors and the role of antibiotic-impregnated catheters for prevention. Am J Infect Control. 2019;47(2):191-5.

19. O'Grady NP, Alexander M, Burns LA, Dellinger EP, Garland J, Heard SO, et al. Summary of recommendations: guidelines for the prevention of intravascular catheter-related infections. Clin Infect Dis. 2011;52(9):1087-99.

20. Chong HY, Lai NM, Apisarnthanarak A, Chaiyakunapruk N. Comparative efficacy of antimicrobial central venous catheters in reducing catheter-related bloodstream infections in adults: abridged cochrane systematic review and network meta-analysis. Clin Infect Dis. 2017;64(suppl_2):S131-S40.

21. Kamboj M, Blair R, Bell N, Son C, Huang YT, Dowling M, et al. Use of disinfection cap to reduce central-line-associated bloodstream infection and blood culture contamination among hematology-oncology patients. Infect Control Hosp Epidemiol. 2015;36(12):1401-8.

22. Merrill KC, Sumner S, Linford L, Taylor C, Macintosh C. Impact of universal disinfectant cap implementation on central line-associated bloodstream infections. Am J Infect Control. 2014;42(12):1274-7.

23. Furuya EY, Dick AW, Herzig CT, Pogorzelska-Maziarz M, Larson EL, Stone PW. Central lineassociated bloodstream infection reduction and bundle compliance in intensive care units: a national study. Infect Control Hosp Epidemiol. 2016;37(7):805-10.

24. Tang HJ, Lin HL, Lin YH, Leung PO, Chuang YC, Lai CC. The impact of central line insertion bundle on central line-associated bloodstream infection. BMC Infect Dis. 2014;14:356.

25. Klintworth G, Stafford J, O'Connor M, Leong T, Hamley L, Watson K, et al. Beyond the intensive care unit bundle: implementation of a successful hospital-wide initiative to reduce central line-associated bloodstream infections. Am J Infect Control. 2014;42(6):685-7.

26. Shea G, Smith W, Koffarnus K, Knobloch MJ, Safdar N. Kamishibai cards to sustain evidence-based practices to reduce healthcare-associated infections. Am J Infect Control. 2019;47(4):358-65.

27. Linder LA, Gerdy C, Jo Y, Wilson A. Changes in central line-associated bloodstream infection rates among children with immune compromised conditions: an 11-year review. J Pediatr Oncol Nurs. 2018;35(6):382-91.

28. Chant C, Smith OM, Marshall JC, Friedrich JO. Relationship of catheter-associated urinary tract infection to mortality and length of stay in critically ill patients: a systematic review and meta-analysis of observational studies. Crit Care Med. 2011;39(5):1167-73.

29. Moghadamyeghaneh Z, Chen LJ, Alameddine M, Gupta AK, Burke GW, Ciancio G. Never events and hospital-acquired conditions after kidney transplant. Can Urol Assoc J. 2017;11(11):E431-E6.

30. Wu X, Dong Y, Liu Y, Li Y, Sun Y, Wang J, et al. The prevalence and predictive factors of urinary tract infection in patients undergoing renal transplantation: a meta-analysis. Am J Infect Control. 2016;44(11):1261-8. 
31. Lee JR, Bang H, Dadhania D, Hartono C, Aull MJ, Satlin M, et al. Independent risk factors for urinary tract infection and for subsequent bacteremia or acute cellular rejection: a single-center report of 1166 kidney allograft recipients. Transplantation. 2013;96(8):732-8.

32. Dantas SR, Kuboyama RH, Mazzali M, Moretti ML. Nosocomial infections in renal transplant patients: risk factors and treatment implications associated with urinary tract and surgical site infections. J Hosp Infect. 2006;63(2):117-23.

33. Lo E, Nicolle LE, Coffin SE, Gould C, Maragakis LL, Meddings J, et al. Strategies to prevent catheter-associated urinary tract infections in acute care hospitals: 2014 update. Infect Control Hosp Epidemiol. 2014;35(5):464-79.

34. Fakih MG, Dueweke C, Meisner S, Berriel-Cass D, Savoy-Moore R, Brach N, et al. Effect of nurse-led multidisciplinary rounds on reducing the unnecessary use of urinary catheterization in hospitalized patients. Infect Control Hosp Epidemiol. 2008;29(9):815-9.

35. Meddings J, Rogers MA, Macy M, Saint S. Systematic review and meta-analysis: reminder systems to reduce catheter-associated urinary tract infections and urinary catheter use in hospitalized patients. Clin Infect Dis. 2010;51(5):550-60.

36. Goldman JD, Julian K. Urinary tract infections in solid organ transplant recipients: guidelines from the American Society of Transplantation Infectious Diseases Community of Practice. Clin Transpl. 2019;33:e13507.

37. Guler S, Cimen S, Hurton S, Molinari M. Risks and benefits of early catheter removal after renal transplantation. Transplant Proc. 2015;47(10):2855-9.

38. Dols JD, White SK, Timmons AL, Bush M, Tripp J, Childers AK, et al. A unique approach to dissemination of evidence-based protocols: a successful CAUTI reduction pilot. J Nurses Prof Dev. 2016;32(1):53-4.

39. Gould CV, Umscheid CA, Agarwal RK, Kuntz G, Pegues DA. Healthcare Infection Control Practices Advisory C. Guideline for prevention of catheter-associated urinary tract infections 2009. Infect Control Hosp Epidemiol. 2010;31(4):319-26.

40. Fasugba O, Cheng AC, Gregory V, Graves N, Koerner J, Collignon P, et al. Chlorhexidine for meatal cleaning in reducing catheter-associated urinary tract infections: a multicentre steppedwedge randomised controlled trial. Lancet Infect Dis. 2019;19(6):611-9.

41. Willson M, Wilde M, Webb ML, Thompson D, Parker D, Harwood J, et al. Nursing interventions to reduce the risk of catheter-associated urinary tract infection: part 2: staff education, monitoring, and care techniques. J Wound Ostomy Cont Nurs. 2009;36(2):137-54.

42. Fakih MG, Krein SL, Edson B, Watson SR, Battles JB, Saint S. Engaging health care workers to prevent catheter-associated urinary tract infection and avert patient harm. Am J Infect Control. 2014;42(10 Suppl):S223-9.

43. Brown K, Valenta K, Fisman D, Simor A, Daneman N. Hospital ward antibiotic prescribing and the risks of Clostridium difficile infection. JAMA Intern Med. 2015;175(4):626-33.

44. Donnelly JP, Wang HE, Locke JE, Mannon RB, Safford MM, Baddley JW. Hospital-onset Clostridium difficile infection among solid organ transplant recipients. Am J Transplant. 2015;15(11):2970-7.

45. Ilett EE, Helleberg M, Reekie J, Murray DD, Wulff SM, Khurana MP, et al. Incidence rates and risk factors of Clostridioides difficile infection in solid organ and hematopoietic stem cell transplant recipients. Open Forum Infect Dis. 2019;6(4):ofz086.

46. Furuya-Kanamori L, Marquess J, Yakob L, Riley TV, Paterson DL, Foster NF, et al. Asymptomatic Clostridium difficile colonization: epidemiology and clinical implications. BMC Infect Dis. 2015;15:516.

47. Revolinski SL, Munoz-Price LS. Clostridium difficile in immunocompromised hosts: a review of epidemiology, risk factors, treatment, and prevention. Clin Infect Dis. 2019;68 (12):2144-53.

48. Jain T, Croswell C, Urday-Cornejo V, Awali R, Cutright J, Salimnia H, et al. Clostridium difficile colonization in hematopoietic stem cell transplant recipients: a prospective study of the epidemiology and outcomes involving toxigenic and nontoxigenic strains. Biol Blood Marrow Transplant. 2016;22(1):157-63. 
49. McDonald LC, Gerding DN, Johnson S, Bakken JS, Carroll KC, Coffin SE, et al. Clinical practice guidelines for Clostridium difficile infection in adults and children: 2017 update by the Infectious Diseases Society of America (IDSA) and Society for Healthcare Epidemiology of America (SHEA). Clin Infect Dis. 2018;66(7):987-94.

50. Anderson DJ, Moehring RW, Weber DJ, Lewis SS, Chen LF, Schwab JC, et al. Effectiveness of targeted enhanced terminal room disinfection on hospital-wide acquisition and infection with multidrug-resistant organisms and Clostridium difficile: a secondary analysis of a multicentre cluster randomised controlled trial with crossover design (BETR disinfection). Lancet Infect Dis. 2018;18(8):845-53.

51. Brite J, McMillen T, Robilotti E, Sun J, Chow HY, Stell F, et al. Effectiveness of ultraviolet disinfection in reducing hospital-acquired Clostridium difficile and vancomycin-resistant Enterococcus on a bone marrow transplant unit. Infect Control Hosp Epidemiol. 2018;39(11):1301-6.

52. Ray AJ, Deshpande A, Fertelli D, Sitzlar BM, Thota P, Sankar CT, et al. A multicenter randomized trial to determine the effect of an environmental disinfection intervention on the incidence of healthcare-associated Clostridium difficile infection. Infect Control Hosp Epidemiol. 2017;38(7):777-83.

53. Abbo LM, Grossi PA, Practice AICo. Surgical site infections: guidelines from the American Society of Transplantation Infectious Diseases Community of Practice. Clin Transpl. 2019;33: e13589.

54. Berrios-Torres SI, Umscheid CA, Bratzler DW, Leas B, Stone EC, Kelz RR, et al. Centers for disease control and prevention guideline for the prevention of surgical site infection, 2017. JAMA Surg. 2017;152(8):784-91.

55. Munoz-Price LS, Bowdle A, Johnston BL, Bearman G, Camins BC, Dellinger EP, et al. Infection prevention in the operating room anesthesia work area. Infect Control Hosp Epidemiol. 2019;40(1):1-17.

56. Schweizer ML, Chiang HY, Septimus E, Moody J, Braun B, Hafner J, et al. Association of a bundled intervention with surgical site infections among patients undergoing cardiac, hip, or knee surgery. JAMA. 2015;313(21):2162-71.

57. Clancy CJ, Bartsch SM, Nguyen MH, Stuckey DR, Shields RK, Lee BY. A computer simulation model of the cost-effectiveness of routine Staphylococcus aureus screening and decolonization among lung and heart-lung transplant recipients. Eur J Clin Microbiol Infect Dis. 2014;33(6):1053-61.

58. Paterson DL, Rihs JD, Squier C, Gayowski T, Sagnimeni A, Singh N. Lack of efficacy of mupirocin in the prevention of infections with Staphylococcus aureus in liver transplant recipients and candidates. Transplantation. 2003;75(2):194-8.

59. Anesi JA, Blumberg EA, Abbo LM. Perioperative antibiotic prophylaxis to prevent surgical site infections in solid organ transplantation. Transplantation. 2018;102(1):21-34.

60. Bratzler DW, Dellinger EP, Olsen KM, Perl TM, Auwaerter PG, Bolon MK, et al. Clinical practice guidelines for antimicrobial prophylaxis in surgery. Am J Health Syst Pharm. 2013;70(3):195-283.

61. Fernandes Agreli H, Murphy M, Creedon S, Ni Bhuachalla C, O’Brien D, Gould D, et al. Patient involvement in the implementation of infection prevention and control guidelines and associated interventions: a scoping review. BMJ Open. 2019;9(3):e025824.

62. Tartari E, Weterings V, Gastmeier P, Rodriguez Bano J, Widmer A, Kluytmans J, et al. Patient engagement with surgical site infection prevention: an expert panel perspective. Antimicrob Resist Infect Control. 2017;6:45.

63. Beam E, Razonable RR. A survey of infection prevention and control practices among solid organ transplantation centers. Am J Infect Control. 2019;47(1):101-4.

64. Duffy J, Harris J, Gade L, Sehulster L, Newhouse E, O'Connell H, et al. Mucormycosis outbreak associated with hospital linens. Pediatr Infect Dis J. 2014;33(5):472-6. 
65. Cheng VCC, Chen JHK, Wong SCY, Leung SSM, So SYC, Lung DC, et al. Hospital outbreak of pulmonary and cutaneous zygomycosis due to contaminated linen items from substandard laundry. Clin Infect Dis. 2016;62(6):714-21.

66. Sehulster L, Chinn RY, Cdc, Hicpac. Guidelines for environmental infection control in healthcare facilities. Recommendations of $\mathrm{CDC}$ and the Healthcare Infection Control Practices Advisory Committee (HICPAC). MMWR Recomm Rep. 2003;52(RR-10):1-42.

67. Freifeld AG, Bow EJ, Sepkowitz KA, Boeckh MJ, Ito JI, Mullen CA, et al. Clinical practice guideline for the use of antimicrobial agents in neutropenic patients with cancer: 2010 update by the Infectious Diseases Society of America. Clin Infect Dis. 2011;52(4):427-31.

68. Gayet-Ageron A, Iten A, van Delden C, Farquet N, Masouridi-Levrat S, Von Dach E, et al. Inhospital transfer is a risk factor for invasive filamentous fungal infection among hospitalized patients with hematological malignancies: a matched case-control study. Infect Control Hosp Epidemiol. 2015;36(3):320-8.

69. Pokala HR, Leonard D, Cox J, Metcalf P, McClay J, Siegel J, et al. Association of hospital construction with the development of healthcare associated environmental mold infections (HAEMI) in pediatric patients with leukemia. Pediatr Blood Cancer. 2014;61(2):276-80.

70. Kanamori H, Rutala WA, Sickbert-Bennett EE, Weber DJ. Review of fungal outbreaks and infection prevention in healthcare settings during construction and renovation. Clin Infect Dis. 2015;61(3):433-44.

71. Ananda-Rajah MR, Bergmeir C, Petitjean F, Slavin MA, Thursky KA, Webb GI. Toward electronic surveillance of invasive mold diseases in hematology-oncology patients: an expert system combining natural language processing of chest computed tomography reports, microbiology, and antifungal drug data. JCO Clin Cancer Inform. 2017;1:1-10.

72. Kanamori H, Weber DJ, Rutala WA. Healthcare outbreaks associated with a water reservoir and infection prevention strategies. Clin Infect Dis. 2016;62(11):1423-35.

73. Falkinham JO 3rd. Common features of opportunistic premise plumbing pathogens. Int $\mathrm{J}$ Environ Res Public Health. 2015;12(5):4533-45.

74. Almeida D, Cristovam E, Caldeira D, Ferreira JJ, Marques T. Are there effective interventions to prevent hospital-acquired Legionnaires' disease or to reduce environmental reservoirs of Legionella in hospitals? A systematic review. Am J Infect Control. 2016;44(11):e183-e8.

75. Shih HY, Lin YE. Efficacy of copper-silver ionization in controlling biofilm- and planktonassociated waterborne pathogens. Appl Environ Microbiol. 2010;76(6):2032-5.

76. Duda S, Kandiah S, Stout JE, Baron JL, Yassin M, Fabrizio M, et al. Evaluation of a new monochloramine generation system for controlling Legionella in building hot water systems. Infect Control Hosp Epidemiol. 2014;35(11):1356-63.

77. Demirjian A, Lucas CE, Garrison LE, Kozak-Muiznieks NA, States S, Brown EW, et al. The importance of clinical surveillance in detecting Legionnaires' disease outbreaks: a large outbreak in a hospital with a Legionella disinfection system-Pennsylvania, 2011-2012. Clin Infect Dis. 2015;60(11):1596-602.

78. Baron JL, Vikram A, Duda S, Stout JE, Bibby K. Shift in the microbial ecology of a hospital hot water system following the introduction of an on-site monochloramine disinfection system. PLoS One. 2014;9(7):e102679.

79. Cristino S, Legnani PP, Leoni E. Plan for the control of Legionella infections in long-term care facilities: role of environmental monitoring. Int J Hyg Environ Health. 2012;215(3):279-85.

80. Dyck A, Exner M, Kramer A. Experimental based experiences with the introduction of a water safety plan for a multi-located university clinic and its efficacy according to WHO recommendations. BMC Public Health. 2007;7:34.

81. Oren I, Zuckerman T, Avivi I, Finkelstein R, Yigla M, Rowe JM. Nosocomial outbreak of Legionella pneumophila serogroup 3 pneumonia in a new bone marrow transplant unit: evaluation, treatment and control. Bone Marrow Transplant. 2002;30(3):175-9.

82. Knirsch CA, Jakob K, Schoonmaker D, Kiehlbauch JA, Wong SJ, Della-Latta P, et al. An outbreak of Legionella micdadei pneumonia in transplant patients: evaluation, molecular epidemiology, and control. Am J Med. 2000;108(4):290-5. 
83. Palmore TN, Stock F, White M, Bordner M, Michelin A, Bennett JE, et al. A cluster of cases of nosocomial legionnaires disease linked to a contaminated hospital decorative water fountain. Infect Control Hosp Epidemiol. 2009;30(8):764-8.

84. Soda EA, Barskey AE, Shah PP, Schrag S, Whitney CG, Arduino MJ, et al. Vital signs: health care-associated Legionnaires' disease surveillance data from 20 states and a large metropolitan area-United States, 2015. Am J Transplant. 2017;17(8):2215-20.

85. Iroh Tam PY, Kline S, Wagner JE, Guspiel A, Streifel A, Ward G, et al. Rapidly growing mycobacteria among pediatric hematopoietic cell transplant patients traced to the hospital water supply. Pediatr Infect Dis J. 2014;33(10):1043-6.

86. Kline S, Cameron S, Streifel A, Yakrus MA, Kairis F, Peacock K, et al. An outbreak of bacteremias associated with Mycobacterium mucogenicum in a hospital water supply. Infect Control Hosp Epidemiol. 2004;25(12):1042-9.

87. Baker AW, Lewis SS, Alexander BD, Chen LF, Wallace RJ Jr, Brown-Elliott BA, et al. Twophase hospital-associated outbreak of Mycobacterium abscessus: investigation and mitigation. Clin Infect Dis. 2017;64(7):902-11.

88. Allen KB, Yuh DD, Schwartz SB, Lange RA, Hopkins R, Bauer K, et al. Nontuberculous mycobacterium infections associated with heater-cooler devices. Ann Thorac Surg. 2017;104(4):1237-42.

89. Wong V, Levi K, Baddal B, Turton J, Boswell TC. Spread of Pseudomonas fluorescens due to contaminated drinking water in a bone marrow transplant unit. J Clin Microbiol. 2011;49(6):2093-6.

90. Lyytikainen O, Golovanova V, Kolho E, Ruutu P, Sivonen A, Tiittanen L, et al. Outbreak caused by tobramycin-resistant Pseudomonas aeruginosa in a bone marrow transplantation unit. Scand J Infect Dis. 2001;33(6):445-9.

91. Decraene V, Phan HTT, George R, Wyllie DH, Akinremi O, Aiken Z, et al. A large, refractory nosocomial outbreak of Klebsiella pneumoniae carbapenemase-producing Escherichia coli demonstrates carbapenemase gene outbreaks involving sink sites require novel approaches to infection control. Antimicrob Agents Chemother. 2018;62(12)

92. Snitkin ES, Zelazny AM, Thomas PJ, Stock F, Henderson DK, Palmore TN, et al. Tracking a hospital outbreak of carbapenem-resistant Klebsiella pneumoniae with whole-genome sequencing. Sci Transl Med. 2012;4(148):148ra16.

93. Leitner E, Zarfel G, Luxner J, Herzog K, Pekard-Amenitsch S, Hoenigl M, et al. Contaminated handwashing sinks as the source of a clonal outbreak of KPC-2-producing Klebsiella oxytoca on a hematology ward. Antimicrob Agents Chemother. 2015;59(1):714-6.

94. Cadnum JL, Shaikh AA, Piedrahita CT, Sankar T, Jencson AL, Larkin EL, et al. Effectiveness of disinfectants against Candida auris and other Candida species. Infect Control Hosp Epidemiol. 2017;38(10):1240-3.

95. Nellore A, Huprikar S, Practice AICo. Vancomycin-resistant Enterococcus in solid organ transplant recipients: guidelines from the American Society of Transplantation Infectious Diseases Community of Practice. Clin Transpl. 2019;33:e13549.

96. Marzec NS, Bessesen MT. Risk and outcomes of methicillin-resistant Staphylococcus aureus (MRSA) bacteremia among patients admitted with and without MRSA nares colonization. Am J Infect Control. 2016;44(4):405-8.

97. Vigil DI, Harden WD, Hines AE, Hosokawa PW, Henderson WG, Bessesen MT. Risk of MRSA infection in patients with intermittent versus persistent MRSA Nares colonization. Infect Control Hosp Epidemiol. 2015;36(11):1292-7.

98. Lam JC, Gregson DB, Robinson S, Somayaji R, Conly JM, Parkins MD. Epidemiology and outcome determinants of Staphylococcus aureus bacteremia revisited: a population-based study. Infection. 2019;47:961-71.

99. Austin ED, Sullivan SS, Macesic N, Mehta M, Miko BA, Nematollahi S, et al. Reduced mortality of Staphylococcus aureus bacteremia in a retrospective cohort study of 2139 patients: 2007-2015. Clin Infect Dis. 2019. 
100. Pereira MR, Rana MM, Practice AICo. Methicillin-resistant Staphylococcus aureus in solid organ transplantation-Guidelines from the American Society of Transplantation Infectious Diseases Community of Practice. Clin Transpl. 2019;33:e13611.

101. Klevens RM, Edwards JR, Tenover FC, McDonald LC, Horan T, Gaynes R, et al. Changes in the epidemiology of methicillin-resistant Staphylococcus aureus in intensive care units in US hospitals, 1992-2003. Clin Infect Dis. 2006;42(3):389-91.

102. Gaynes R, Edwards JR, National Nosocomial Infections Surveillance S. Overview of nosocomial infections caused by gram-negative bacilli. Clin Infect Dis. 2005;41(6):848-54 .

103. Cornaglia G, Giamarellou H, Rossolini GM. Metallo-beta-lactamases: a last frontier for betalactams? Lancet Infect Dis. 2011;11(5):381-93.

104. Sievert DM, Ricks P, Edwards JR, Schneider A, Patel J, Srinivasan A, et al. Antimicrobialresistant pathogens associated with healthcare-associated infections: summary of data reported to the National Healthcare Safety Network at the Centers for Disease Control and Prevention, 2009-2010. Infect Control Hosp Epidemiol. 2013;34(1):1-14.

105. Weiner LM, Webb AK, Limbago B, Dudeck MA, Patel J, Kallen AJ, et al. Antimicrobialresistant pathogens associated with healthcare-associated infections: summary of data reported to the National Healthcare Safety Network at the Centers for Disease Control and Prevention, 2011-2014. Infect Control Hosp Epidemiol. 2016;37(11):1288-301.

106. Kalpoe JS, Sonnenberg E, Factor SH, del Rio MJ, Schiano T, Patel G, et al. Mortality associated with carbapenem-resistant Klebsiella pneumoniae infections in liver transplant recipients. Liver Transpl. 2012;18(4):468-74.

107. Patel G, Huprikar S, Factor SH, Jenkins SG, Calfee DP. Outcomes of carbapenem-resistant Klebsiella pneumoniae infection and the impact of antimicrobial and adjunctive therapies. Infect Control Hosp Epidemiol. 2008;29(12):1099-106.

108. Lanini S, Costa AN, Puro V, Procaccio F, Grossi PA, Vespasiano F, et al. Incidence of carbapenem-resistant gram negatives in Italian transplant recipients: a nationwide surveillance study. PLoS One. 2015;10(4):e0123706.

109. Pouch SM, Patel G. Multidrug-resistant Gram-negative bacterial infections in solid organ transplant recipients-Guidelines from the American Society of Transplantation Infectious Diseases Community of Practice. Clin Transpl. 2019;33:e13594.

110. Scheich S, Lindner S, Koenig R, Reinheimer C, Wichelhaus TA, Hogardt M, et al. Clinical impact of colonization with multidrug-resistant organisms on outcome after allogeneic stem cell transplantation in patients with acute myeloid leukemia. Cancer. 2018;124(2):286-96.

111. Russell DL, Flood A, Zaroda TE, Acosta C, Riley MM, Busuttil RW, et al. Outcomes of colonization with MRSA and VRE among liver transplant candidates and recipients. Am J Transplant. 2008;8(8):1737-43.

112. Ziakas PD, Pliakos EE, Zervou FN, Knoll BM, Rice LB, Mylonakis E. MRSA and VRE colonization in solid organ transplantation: a meta-analysis of published studies. Am J Transplant. 2014;14(8):1887-94.

113. Macesic N, Gomez-Simmonds A, Sullivan SB, Giddins MJ, Ferguson SA, Korakavi G, et al. Genomic surveillance reveals diversity of multidrug-resistant organism colonization and infection: a prospective cohort study in liver transplant recipients. Clin Infect Dis. 2018;67(6):905-12.

114. Giannella M, Bartoletti M, Morelli MC, Tedeschi S, Cristini F, Tumietto F, et al. Risk factors for infection with carbapenem-resistant Klebsiella pneumoniae after liver transplantation: the importance of pre- and posttransplant colonization. Am J Transplant. 2015;15(6):1708-15.

115. Siegel JD, Rhinehart E, Jackson M, Chiarello L, Health Care Infection Control Practices Advisory C. 2007 guideline for isolation precautions: preventing transmission of infectious agents in health care settings. Am J Infect Control. 2007;35(10 Suppl 2):S65-164.

116. Centers for Disease C, Prevention. Guidance for control of infections with carbapenemresistant or carbapenemase-producing Enterobacteriaceae in acute care facilities. MMWR Morb Mortal Wkly Rep. 2009;58(10):256-60. 
117. Carmeli Y, Akova M, Cornaglia G, Daikos GL, Garau J, Harbarth S, et al. Controlling the spread of carbapenemase-producing Gram-negatives: therapeutic approach and infection control. Clin Microbiol Infect. 2010;16(2):102-11.

118. Tschudin-Sutter S, Lucet JC, Mutters NT, Tacconelli E, Zahar JR, Harbarth S. Contact precautions for preventing nosocomial transmission of extended-spectrum beta lactamaseproducing Escherichia coli: a point/counterpoint review. Clin Infect Dis. 2017;65(2):342-7.

119. Huskins WC, Huckabee CM, O'Grady NP, Murray P, Kopetskie H, Zimmer L, et al. Intervention to reduce transmission of resistant bacteria in intensive care. $\mathrm{N}$ Engl $\mathrm{J}$ Med. 2011;364(15):1407-18.

120. Bearman G, Abbas S, Masroor N, Sanogo K, Vanhoozer G, Cooper K, et al. Impact of discontinuing contact precautions for methicillin-resistant Staphylococcus aureus and vancomycin-resistant Enterococcus: an interrupted time series analysis. Infect Control Hosp Epidemiol. 2018;39(6):676-82.

121. Marra AR, Edmond MB, Schweizer ML, Ryan GW, Diekema DJ. Discontinuing contact precautions for multidrug-resistant organisms: a systematic literature review and meta-analysis. Am J Infect Control. 2018;46(3):333-40.

122. De Angelis G, Cataldo MA, De Waure C, Venturiello S, La Torre G, Cauda R, et al. Infection control and prevention measures to reduce the spread of vancomycin-resistant enterococci in hospitalized patients: a systematic review and meta-analysis. J Antimicrob Chemother. 2014;69(5):1185-92.

123. Stelfox HT, Bates DW, Redelmeier DA. Safety of patients isolated for infection control. JAMA. 2003;290(14):1899-905.

124. Abbo L, Shukla BS, Giles A, Aragon L, Jimenez A, Camargo JF, et al. Linezolid- and vancomycin-resistant Enterococcus faecium in solid organ transplant recipients: infection control and antimicrobial stewardship using whole genome sequencing. Clin Infect Dis. 2019;69(2):259-65.

125. Ben-David D, Masarwa S, Fallach N, Temkin E, Solter E, Carmeli Y, et al. Success of a national intervention in controlling carbapenem-resistant Enterobacteriaceae in Israel's longterm care facilities. Clin Infect Dis. 2019;68(6):964-71.

126. van Loon K, Voor In 't Holt AF, Vos MC. A systematic review and meta-analyses of the clinical epidemiology of carbapenem-resistant Enterobacteriaceae. Antimicrob Agents Chemother. 2018;62(12). pii: e01689-18. https://doi.org/10.1128/AAC.01689-18. Print 2018 Dec.

127. van Duin D, van Delden C, Practice ASTIDCo. Multidrug-resistant gram-negative bacteria infections in solid organ transplantation. Am J Transplant. 2013;13(Suppl 4):31-41.

128. Huang SS, Septimus E, Kleinman K, Moody J, Hickok J, Avery TR, et al. Targeted versus universal decolonization to prevent ICU infection. N Engl J Med. 2013;368(24):2255-65.

129. Singh N, Squier C, Wannstedt C, Keyes L, Wagener MM, Cacciarelli TV. Impact of an aggressive infection control strategy on endemic Staphylococcus aureus infection in liver transplant recipients. Infect Control Hosp Epidemiol. 2006;27(2):122-6.

130. Abbas S, Raybould JE, Sastry S, de la Cruz O. Respiratory viruses in transplant recipients: more than just a cold. Clinical syndromes and infection prevention principles. Int J Infect Dis. 2017;62:86-93.

131. Manuel O, Estabrook M, American Society of Transplantation Infectious Diseases Community of P. RNA respiratory viral infections in solid organ transplant recipients: guidelines from the American Society of Transplantation Infectious Diseases Community of Practice. Clin Transpl. 2019;33:e13511.

132. Sokol KA, De la Vega-Diaz I, Edmondson-Martin K, Kim S, Tindle S, Wallach F, et al. Masks for prevention of respiratory viruses on the BMT unit: results of a quality initiative. Transpl Infect Dis. 2016;18(6):965-7.

133. Offeddu V, Yung CF, Low MSF, Tam CC. Effectiveness of masks and respirators against respiratory infections in healthcare workers: a systematic review and meta-analysis. Clin Infect Dis. 2017;65(11):1934-42. 
134. Smith JD, MacDougall CC, Johnstone J, Copes RA, Schwartz B, Garber GE. Effectiveness of N95 respirators versus surgical masks in protecting health care workers from acute respiratory infection: a systematic review and meta-analysis. CMAJ. 2016;188(8):567-74.

135. Kumar D, Michaels MG, Morris MI, Green M, Avery RK, Liu C, et al. Outcomes from pandemic influenza A H1N1 infection in recipients of solid-organ transplants: a multicentre cohort study. Lancet Infect Dis. 2010;10(8):521-6.

136. Reid G, Huprikar S, Patel G, Razonable RR, Mossad S, Levi M, et al. A multicenter evaluation of pandemic influenza A/H1N1 in hematopoietic stem cell transplant recipients. Transpl Infect Dis. 2013;15(5):487-92.

137. Uyeki TM, Bernstein HH, Bradley JS, Englund JA, File TM, Fry AM, et al. Clinical practice guidelines by the infectious diseases Society of America: 2018 update on diagnosis, treatment, chemoprophylaxis, and institutional outbreak management of seasonal influenzaa. Clin Infect Dis. 2019;68(6):e1-e47.

138. Bosaeed M, Kumar D. Seasonal influenza vaccine in immunocompromised persons. Hum Vaccin Immunother. 2018;14(6):1311-22.

139. Kumar D, Ferreira VH, Blumberg E, Silveira F, Cordero E, Perez-Romero P, et al. A 5-year prospective multicenter evaluation of influenza infection in transplant recipients. Clin Infect Dis. 2018;67(9):1322-9.

140. Danziger-Isakov L, Kumar D, Practice AICo. Vaccination of solid organ transplant candidates and recipients: guidelines from the American society of transplantation infectious diseases community of practice. Clin Transpl. 2019;33:e13563.

141. Natori Y, Shiotsuka M, Slomovic J, Hoschler K, Ferreira V, Ashton P, et al. A double-blind, randomized trial of high-dose vs standard-dose influenza vaccine in adult solid-organ transplant recipients. Clin Infect Dis. 2018;66(11):1698-704.

142. Radonovich LJ Jr, Simberkoff MS, Bessesen MT, Brown AC, Cummings DAT, Gaydos CA, et al. N95 respirators vs medical masks for preventing influenza among health care personnel: a randomized clinical trial. JAMA. 2019;322(9):824-33.

143. Khawaja F, Chemaly RF. Respiratory syncytial virus in hematopoietic cell transplant recipients and patients with hematologic malignancies. Haematologica. 2019;104:1322-31.

144. Kelly SG, Metzger K, Bolon MK, Silkaitis C, Mielnicki M, Cullen J, et al. Respiratory syncytial virus outbreak on an adult stem cell transplant unit. Am J Infect Control. 2016;44(9):1022-6.

145. French CE, McKenzie BC, Coope C, Rajanaidu S, Paranthaman K, Pebody R, et al. Risk of nosocomial respiratory syncytial virus infection and effectiveness of control measures to prevent transmission events: a systematic review. Influenza Other Respir Viruses. 2016;10(4):268-90.

146. Michaels MG, Fonseca-Aten M, Green M, Charsha-May D, Friedman B, Seikaly M, et al. Respiratory syncytial virus prophylaxis: a survey of pediatric solid organ transplant centers. Pediatr Transplant. 2009;13(4):451-6.

147. Danziger-Isakov LA, Arslan D, Sweet S, Benden C, Goldfarb S, Wong J. RSV prevention and treatment in pediatric lung transplant patients: a survey of current practices among the International Pediatric Lung Transplant Collaborative. Pediatr Transplant. 2012;16(6):638-44.

148. Teusink-Cross A, Davies SM, Danziger-Isakov L, El-Bietar J, Grimley MS. Restrictive palivizumab use does not lead to increased morbidity and mortality in pediatric hematopoietic stem cell transplantation patients. Biol Blood Marrow Transplant. 2016;22(10):1904-6.

149. American Academy of Pediatrics Committee on Infectious Diseases, American Academy of Pediatrics Bronchiolitis Guidelines Committee. Updated guidance for palivizumab prophylaxis among infants and young children at increased risk of hospitalization for respiratory syncytial virus infection. Pediatrics. 2014;134(2):415-20.

150. Science M, Akseer N, Asner S, Allen U. Risk stratification of immunocompromised children, including pediatric transplant recipients at risk of severe respiratory syncytial virus disease. Pediatr Transplant. 2019;23(2):e13336. 
151. Kassis C, Champlin RE, Hachem RY, Hosing C, Tarrand JJ, Perego CA, et al. Detection and control of a nosocomial respiratory syncytial virus outbreak in a stem cell transplantation unit: the role of palivizumab. Biol Blood Marrow Transplant. 2010;16(9):1265-71.

152. Ison MG. Adenovirus infections in transplant recipients. Clin Infect Dis. 2006;43(3):331-9.

153. Lion T. Adenovirus infections in immunocompetent and immunocompromised patients. Clin Microbiol Rev. 2014;27(3):441-62.

154. Florescu DF, Schaenman JM, Practice ASTIDCo. Adenovirus in solid organ transplant recipients: guidelines from the American Society of Transplantation Infectious Diseases Community of Practice. Clin Transpl. 2019;33:e13527.

155. Rutala WA, Peacock JE, Gergen MF, Sobsey MD, Weber DJ. Efficacy of hospital germicides against adenovirus 8, a common cause of epidemic keratoconjunctivitis in health care facilities. Antimicrob Agents Chemother. 2006;50(4):1419-24.

156. Pergam SA, Limaye AP. Varicella zoster virus (VZV) in solid organ transplantation: guidelines from the American society of transplantation infectious diseases community of practice. Clin Transpl. 2019;33:e13622.

157. Cordonnier C, Einarsdottir S, Cesaro S, Di Blasi R, Mikulska M, Rieger C, et al. Vaccination of haemopoietic stem cell transplant recipients: guidelines of the 2017 European Conference on Infections in Leukaemia (ECIL 7). Lancet Infect Dis. 2019;19(6):e200-e12.

158. Chong PP, Avery RK. A comprehensive review of immunization practices in solid organ transplant and hematopoietic stem cell transplant recipients. Clin Ther. 2017;39(8):1581-98.

159. Advisory Committee on Immunization Practices, Centers for Disease Control and Prevention (CDC). Immunization of health-care personnel: recommendations of the Advisory Committee on Immunization Practices (ACIP). MMWR Recomm Rep. 2011;60(RR-7):1-45.

160. Marin M, Guris D, Chaves SS, Schmid S, Seward JF, Advisory Committee on Immunization Practices CfDC, et al. Prevention of varicella: recommendations of the Advisory Committee on Immunization Practices (ACIP). MMWR Recomm Rep. 2007;56(RR-4):1-40.

161. Paules CI, Marston HD, Fauci AS. Measles in 2019 - going backward. N Engl J Med. 2019;380(23):2185-7.

162. Patel M, Lee AD, Redd SB, Clemmons NS, McNall RJ, Cohn AC, et al. Increase in measles cases - United States, January 1-April 26, 2019. MMWR Morb Mortal Wkly Rep. 2019;68(17):402-4.

163. McLean HQ, Fiebelkorn AP, Temte JL, Wallace GS, Centers for Disease C, Prevention. Prevention of measles, rubella, congenital rubella syndrome, and mumps, 2013: summary recommendations of the Advisory Committee on Immunization Practices (ACIP). MMWR Recomm Rep. 2013;62(RR-04):1-34.

164. Han G, Batra N, Vallejo A, Schechter R, Zipprich J, Harriman K. Notes from the field: measles outbreak in an era of stricter immunization requirements - California, March 2018. MMWR Morb Mortal Wkly Rep. 2019;68(8):201-2.

165. Fiebelkorn AP, Seward JF, Orenstein WA. A global perspective of vaccination of healthcare personnel against measles: systematic review. Vaccine. 2014;32(38):4823-39.

166. Basu S, Giri P, Adisesh A, Mc NR. Healthcare workers and measles-mumps-rubella (MMR) status: how worried should we be about further outbreaks? Epidemiol Infect. 2014;142(8):1688-94. 